\title{
The Waiting Game - How Cooperation Between Public and Private Hospitals Can Help Reduce Waiting Lists
}

\author{
Jorge A. Acuna ${ }^{1}$ (i) . José L. Zayas-Castro ${ }^{1}$ - Felipe Feijoo ${ }^{2}$. Sriram Sankaranarayanan ${ }^{3} \cdot$ Rodrigo Martinez $^{4}$. \\ Diego A. Martinez $z^{2,5}$
}

Received: 8 May 2020 / Accepted: 22 July 2021 / Published online: 17 August 2021

(C) The Author(s), under exclusive licence to Springer Science+Business Media, LLC, part of Springer Nature 2021

\begin{abstract}
Prolonged waiting to access health care is a primary concern for nations aiming for comprehensive effective care, due to its adverse effects on mortality, quality of life, and government approval. Here, we propose two novel bargaining frameworks to reduce waiting lists in two-tier health care systems with local and regional actors. In particular, we assess the impact of 1) trading patients on waiting lists among hospitals, the 2) introduction of the role of private hospitals in capturing unfulfilled demand, and the 3) hospitals' willingness to share capacity on the system performance. We calibrated our models with 2008-2018 Chilean waiting list data. If hospitals trade unattended patients, our game-theoretic models indicate a potential reduction of waiting lists of up to $37 \%$. However, when private hospitals are introduced into the system, we found a possible reduction of waiting lists of up to $60 \%$. Further analyses revealed a trade-off between diagnosing unserved demand and the additional expense of using private hospitals as a back-up system. In summary, our game-theoretic frameworks of waiting list management in two-tier health systems suggest that public-private cooperation can be an effective mechanism to reduce waiting lists. Further empirical and prospective evaluations are needed.
\end{abstract}

Keywords Game theory · Operations research · Waiting lists · Universal health care · Health care delivery · Health economics

\section{Highlights}

- We study the global crisis of waiting lists for specialized medical services.

- We introduce two new quantitative frameworks to reduce waiting lists that are associated with high mortality.

Jorge A. Acuna

jorge@usf.edu

1 Industrial and Management Systems Engineering, University of South Florida, 4202 E. Fowler Avenue, Tampa, FL, 33620, USA

2 School of Industrial Engineering, Pontificia Universidad Católica de Valparaíso, Valparaíso, Chile

3 Production and Quantitative Methods, Indian Institute of Management, Ahmedabad, India

4 Escuela de Salud Pública, Universidad de Chile, Santiago, Chile

5 Department of Emergency Medicine, Johns Hopkins University, Baltimore, Maryland, USA
- Our formulation considers patient and hospital characteristics, local and regional negotiations, the role of private providers, resource location, and hospitals' willingness to share capacity.

- We show that our game-theoretic models can substantially improve patient care, reducing waiting lists by up to $60 \%$.

- We provide mechanisms that can fit different countries' socio-political needs and spur cooperation among hospitals.

\section{Introduction}

In the last decades, waiting lists for elective medical services have been a major concern of governments and publicly funded health systems. Consequently, various studies and policy implementations have been undertaken to mitigate the problem and its effects on the population [1-4]. For policymakers, waiting lists represent an issue that provokes public disapproval of government and politicians [5]. Researchers, have spent more than a century trying to find 
explanations to the waiting list problem and observing the negative effects on society [6].

The waiting list problem exists in developing countries, such as Chile, Brazil, and India, and in developed countries, such as England, Canada, and Australia [1, 7-9]. According to the Organization for Economic Cooperation and Development (OECD), waiting lists are even worse in countries combining public insurance and low or zero patient cost sharing [10], which are common methods to control access to care [11].

In this context, countries implementing universal health coverage (UHC) are in greater need of having a technical infrastructure to handle waiting lists compared to countries that ration their resources through the financial ability of patients to access care (e.g., the United States) [10, 12]. The main idea behind UHC is to increase access to and the quality of health services while reducing the financial burden on patients [13]. Currently, the World Bank and the World Health Organization provide technical assistance to more than 100 countries for the implementation of UHC. Furthermore, all United Nations members have confirmed the goal of having UHC by 2030 [14].

The increasing worldwide importance of universal medical services underlines the need for adequate strategies to handle waiting lists and improve the utilization of available resources. Recent studies show that waiting lists are associated with increased mortality rates, worse quality of life, and significant emotional trauma [15-19]. Therefore, waiting lists have become a major health concern in many OECD countries [20].

In the present work, we investigate the waiting list problem in relation to specialized medical services in a South American country-Chile- with a two-tier health system. Two mathematical frameworks are proposed to reduce waiting lists, considering system resources, patient conditions and priorities, selfishness in negotiations, and public-to-public and public-to-private hospital patient transfers. Cooperative bargaining is introduced to enhance current system interactions and take advantage of misused resources.

\subsection{Background on waiting list policies}

In the first decade of the new millennium, most efforts to reduce waiting lists have focused on the existence of imbalances between supply and demand. One common approach considers supply-side policies [11]. The idea behind these policies is to increase funding to expand the workforce or the physical capacity of health systems, which helps to mitigate waiting times and increase service rates. However, the evidence has shown that supply-side policies have a limited effect, where a short-term reduction in waiting times is followed by a return to previous conditions or a worsening of conditions as funding runs out [5].
Additionally, the study in [21] shows that the demand for elective procedures is negatively correlated to waiting times and highly elastic, in some cases even more than the supply curve. Consequently, as the population expects a reduction in waiting times, the demand increases and surpasses the capacity increment of supply policies. These experiences have demonstrated that short-term efforts to increase public health expenditure may be unsuccessful in reducing waiting lists for elective medical services. This relates to the inability to address the structural elements that result in waiting lists [5].

Most recent approaches are oriented to demand-side policies or a combination of supply-side and demand-side policies. Demand policies try to define clinical thresholds below which patients do not have access to publicly funded elective medical services or to divert demand to the private system through different mechanisms. Demand-side policies are difficult to implement due to the lack of data infrastructure to define the ability of patients to benefit from medical interventions. Moreover, the need to incentivize private health insurance can represent a socio-political challenge [5, 10]. With a combination of supply-side and demand-side policies, the most promising development is waiting time guarantees [5, 20, 22, 23].

Waiting time guarantees set the maximum time a patient should wait for care. The definitions of times may vary across countries and in general will represent how much a country can invest. In some cases, waiting time guarantees are enforced by governments, but despite these efforts providers may not be able to meet the threshold of time; therefore, the guarantees become more of an aspiration than an actuality [5, 24].

A significant consequence of guaranteeing waiting times is the obligation of health professionals to favor access over need, which conflicts with the Hippocratic oath [25]. Another issue with time guarantee policies is that, in general, they do not consider the equality of suffering. For example, a country might give preference to frequent types of diseases or older groups of patients [22, 2628], leaving patients with more uncommon diseases or low risk populations without funding or timely treatment. Consequently, even longer waiting lists for non-prioritized conditions or patients occur [15].

\subsection{Literature review}

Given the consequences of universal care and the widely implemented waiting time guarantees, we focus our study on models intended to improve the management of waiting lists rather than on the supply, the demand, or the combination of both. The following literature review provides interesting results and increased awareness of the efforts to reduce waiting lists for elective medical services. 
The management of waiting lists can be approached based on the different understandings of the problem. Some studies have proposed focusing on the systemic issues, recognizing the impact that different actors and their relationships might have on social welfare and the importance of financial commitments. The authors in [29] built a reference framework for waiting list management in a public system. The framework included the national, regional, and hospital implications of waiting lists. Additionally, an input-output model was developed to project the demand at the regional level, making it possible to evaluate the impact of waiting lists for different scenarios. The results showed that actors at different levels of decision making can influence the availability of resources in the health system. Consequently, specific models should be designed to support communication and decision making in relation to waiting lists. In [30], a qualitative study using semi-structured interviews was conducted to identify the main factors contributing to waiting lists. The results showed that a balance between demand and supply is essential to achieve better access to medical services; however, such balance is not always feasible due to financial constraints or limited resources. The authors in [31] studied waiting lists as a mechanism to ration demand in health systems; their analysis centers around Pareto optimal wait times, public choice, and queuing theory. The results showed that suppliers, patients, and governments might not maximize social welfare. Using game theory and discrete event simulation, the study in [32] evaluated the impact of patients' choice in health systems. The conclusions highlighted the negative impact that individual/selfish decisions have on waiting times. In [33], the authors explored the benefit of using a non-cooperative game to maximize social welfare in a kidney exchange program. The conclusions evidenced the existence of a Nash equilibrium that was also a social optimum for a two-player setting. The studies presented above have limitations that need to be mentioned. First, most of the studies do not consider the importance of prioritization algorithms. Second, they present the major systemic factors resulting in waiting lists but do not necessarily provide mechanisms to deal with the issue. Third, they do not consider the interactions of a two-tier health system where private hospitals might play a fundamental role in determining waiting lists.

An alternative research line consists of modeling programs or particular hospital settings to reduce waiting lists, highlighting the importance of detailed information about resource availability and the characteristics of waiting lists at each institution. Through multi-objective optimization, the authors in [34] attempted to improve hospital administration efficiency for surgical waiting lists. The model provided an optimal surgical schedule that maximized hospital performance and minimized unusual activities to reduce waiting lists. An analytical framework for decision support systems in relation to surgical plans was also presented. In [35], the authors studied the impact of a new referral system for non-urgent specialist appointments on waiting lists of more than two years. Two options were offered to patients-take no action if the appointment was no longer required or visit a primary physician to get a new referral using a new clinic-specific template. The results showed that the time required to get a specialist appointment was reduced from eight years to two years. Using Monte Carlo simulation, the authors in [36] explored the idea of reducing waiting lists for elective orthopedic procedures by offering earlier treatment in trauma settings that were underutilized. The results showed a possible reduction of $18 \%$ of all elective procedures, thus having a significant effect on waiting times. In [37], the authors proposed a quantum-inspired evolutionary algorithm to optimize the scheduling of elective surgical procedures. The model was tested in a simulated scenario of 2000 surgeries on a waiting list with 25 nursing beds and 10 surgery rooms. The results showed a reduction in waiting time of $16.25 \%$. From the literature above, several contributions have emerged. However, these studies neglect the impact of system interactions, assume isolated environments, and target factors that are not necessarily the real reasons for waiting lists.

The last research line focuses on prioritizing waiting lists, which has become a significant method of improvement for different specialties. This idea includes understanding the role of justice, the severity of a patient's condition, and advanced policy models. In [38], a triage stage was implemented to reduce waiting lists for the first appointment for child mental health services. The study followed 155 patients over six months and compared the results with a control group. The method helped reduce the waiting time for the first appointment significantly, and of the original 155 patients, 82 were removed from the waiting list. In [39], the authors investigated how patients are prioritized under policies of time guarantees. Through empirical analysis of patient-level data, they built a Poisson regression model to relate the number of days patients spend on waiting lists to observed patient characteristics. Their results showed that doctors in general prioritized patients according to the severity of their condition, even when no formal policy for prioritization is in place. In [40], a rule-based prioritization criterion was implemented to improve the management of waiting lists, considering waiting time and justice. The study demonstrated that timeliness considerations are insufficient to manage waiting lists properly and that justice should be included in the prioritization models. Based on the studies above, prioritization techniques have become a key component in improving the management of waiting lists. Nevertheless, prioritization models do not reduce waiting lists unless patients are removed from the queue before 
treatment. The last limitation shows the importance of prioritization models as a complement to techniques aiming to reduce waiting lists.

The reviewed literature focused on three major aspects: the systemic issues or structural elements of waiting lists, models to reduce waiting lists in individual programs or hospital settings, and prioritization techniques to manage waiting lists. Several findings emerged from these efforts: the negative role that isolate decisions play in social welfare, the need to include fairness in mathematical models, and the importance of provider communication in the health system.

\subsection{Contributions}

As shown by [29], actors at different levels of decision making can influence the performance of a health system. In this paper, our objective is to reduce waiting lists for specialized medical services by improving current system interactions. Unlike previous approaches, we integrate patient and hospital characteristics in a framework of local and regional decisions of a two-tier health system. Our models are intended to improve public actors' synergy and integrate the different roles that private providers could play to reduce waiting lists while accounting for patient prioritization. Additionally, we show the consequences of hospitals' selfishness on the system's efficiency. The resulting mathematical models enable health planners and government entities to assess the potential benefits of policy implementation. We illustrate these approaches with a setting in Chile. However, our methodologies and frameworks can be contextually applied to countries with similar structures.

\subsection{The health system of Chile}

Chile has a two-tier health care system, with a public expenditure of $4.5 \%$ of the gross domestic product (GDP). In 2017, for the first time the public health expenditure matched the private health expenditure [41]. Despite this, the imbalance between the demand received by public and private hospitals is still a source of significant inequality [42]. Approximately $78 \%$ of the population is covered by the public network, and the remaining population is covered by private or military insurance $[43,44]$. The public system is divided strategically into six macro-regions to manage the health system. Each macro-region has two or more Regional Health Services (RHSs), with a total of 29 RHSs that administer and supervise the provision of health care at all levels [45].

In 2005, the government of Chile implemented a policy that included waiting time guarantees, known as garantías explícitas en salud (GES, health explicit guarantees), to limit waiting time and the financial burden on patients, while increasing access to and quality of care for a select group of conditions [15, 46-48]. The prioritized health conditions were chosen based mainly on social preference and the level of burden of disease [22]. Today in Chile, 85 conditions are covered by GES [49]. These consume the most public health resources, thus causing lengthy waiting lists for non-prioritized or non-GES conditions [50]. In 2018, the Chilean Ministry of Health registered 1,801,937 patients who did not receive care for non-prioritized elective medical appointments. In the first half of 2018 (JanuaryJune) alone, 9,364 patients died while waiting for treatment [51]. In other words, $18.5 \%$ of the total deaths in Chile were patients waiting for care, and only $3.4 \%$ of the deaths were associated with external causes of mortality [51, 52].

\subsubsection{Operational aspects}

In 2017, the Chilean government defined a set of administrative policies for the national system of RHSs. The idea was to regulate the utilization of public resources considering efficiency and efficacy. The two main additions to the system were the creation of the macro-regional purchasing directories and the incorporation of budget guidelines for the acquisition of health services. Purchasing directories have two main goals-to optimize the purchase of private and public providers' services and to provide technical recommendations vis-à-vis the needs of RHSs. According to the national report [42], during 2017 the purchasing directories produced better coordination among RHSs in terms of resolving waiting lists for specialized medical services, both GES and non-GES. Guideline nine officialized the acquisition of services provided by private providers; however, the idea behind this protocol is to keep track of purchases, and it is not restrictive in nature [42]. Therefore, the purchasing directories evaluate and help coordinate the interaction among public and private providers, including hospitals, while guideline nine makes the financial interaction official.

In parallel to the improvements described above, the government is implementing new information technology, the Sistema de Gestión de Tiempos de Espera (SIGTE, Waiting Times Management System). This platform was designed to keep track of patients on waiting lists and to detect bottlenecks in the network. At the same time, SIGTE provides a solid base for the utilization of electronic medical records throughout the country and should enable the use of prioritization algorithms to reduce mortality associated with waiting lists [51].

From a financial perspective, the two major funds that coexist in the Chilean health system are the Fondo Nacional de Salud (FONASA, National Public Health Fund) and the Instituciones de Salud Previsional (ISAPRES, Private Health Insurers). However, there is no coordination between 
these two systems [53]. The fund assignment process of the public system aims to keep the cost of health services low and to promote high service rates. However, the assignment of funds considers compromises of production (expected number of patients to be served) that are not related to the actual demand but rather to statistics from the previous year. Furthermore, the production that surpasses the annual agreement is not reimbursed. In contrast, a budget that is not entirely utilized implies a reduction in funds for the next year, promoting expenditure over efficiency [54]. In 2020, the first high-complexity hospitals with diagnosis related groups (DRG) systems started transitioning to a new payment mechanism. The idea behind this new approach is to fund hospitals with a fixed amount of the global budget (with limits) and a variable amount based on the number of patients served classified by DRG. This new funding mechanism is expected to increase the hospitals' efficiency and split the financial risk between FONASA and the providers [55].

Based on the information in this section, expert opinions, and a report [56], a graphical representation of system interactions was built. Figure 1 shows two macro-regions with different sets of RHS supervising medical centers providing primary, secondary, and tertiary levels of care. The black arrows represent administrative interactions, while the red arrows represent the movement of patients inside the system. Depending on the existence of agreements with FONASA, private hospitals might be under the monitoring of RHSs or might be supervised directly by the health superintendence. Even if rare, transfers of patients among macro-regions happens when technologies or procedures are not available at specific locations. Similarly, patients on waiting lists might go to private providers in certain circumstances, such as lack of technology in the public system or agreements between FONASA and private providers.

\subsection{Structure}

The rest of the article proceeds as follows. Section 2 introduces the main definitions and methods used in this study. Section 3 describes the mathematical formulation for each framework and the notations needed. Section 4 presents the Chilean case study. Section 5 presents the results of implementing our models in the case study. Finally, Section 6 discusses the main findings and presents the conclusions of this study.

\section{Methods}

Based on the problem description, a combination of consecutive games, machine learning, and multi-objective optimization is implemented to mimic and enhance the health system in Chile, providing alternatives for reducing waiting lists for specialized medical services. We then present some ideas and definitions to facilitate understanding of the methodologies.

\subsection{Preliminaries}

\subsubsection{Multi-objective optimization}

Consider the general formulation of a multi-objective optimization model:

$\max _{z \in \mathcal{Z}} f_{1}(z), f_{2}(z), \ldots ., f_{p}(z)$,

where $\mathcal{Z}$ represents the feasible set in the decision space, and $f_{k}(z)$ is the linear objective function of entity $k$, from $k=1, \ldots, p$. Let us define the image of $\mathcal{Z}$ in the objective/criterion space as $\mathcal{W}=f(\mathcal{Z})$.

Definition: A feasible solution $z^{\prime} \in \mathcal{Z}$ is called efficient or Pareto optimal if there is no other $z \in \mathcal{Z}$ such that $f_{k}(z) \geq f_{k}\left(z^{\prime}\right)$ for $k=1, \ldots, p$ and $f(z) \neq f\left(z^{\prime}\right)$. If $z^{\prime}$ is efficient, then $f\left(z^{\prime}\right)$ is called a nondominated point. The set of all efficient solutions $z^{\prime} \in \mathcal{Z}$ is denoted by $\mathcal{Z}_{E}$. The set of all nondominated points $f\left(z^{\prime}\right) \in \mathcal{W}$ for some $z^{\prime} \in \mathcal{Z}_{E}$ is denoted by $\mathcal{W}_{N}$ and referred to as the nondominated frontier or the efficient frontier [57].

\subsubsection{Nash bargaining solution}

The Nash bargaining solution (NBS) is a cooperative approach to address the bargaining problem in which players need to share a payoff or cost that they jointly generate. In this case, the players create a grand coalition instead of competing with each other to get better payoffs or lower costs. The NBS yields a unique and Pareto optimal solution. Let $u_{k}$ for $k=1, \ldots, p$ be the utility function of player $k$ and $d_{k}$ be the disagreement point or status quo (payoff without cooperation) of player $k$. The NBS is the point $z \in \mathcal{Z}$ obtained from the following optimization problem.

$\max _{z \in \mathcal{Z}} \prod_{k=1}^{p}\left(u_{k}(z)-d_{k}\right)$

Two important axioms relating to bargaining games are individual rationality and Pareto optimality. The first one establishes that no player will accept a payoff lower than the disagreement point. The second introduces the tradeoff among the players when a solution has been obtained. Thus, the solution guarantees that the payoff for one player cannot be increased without negatively affecting the payoffs of other players [58-60].

As mentioned, we use a sequential approach to model the waiting list for specialized medical services. This implies 


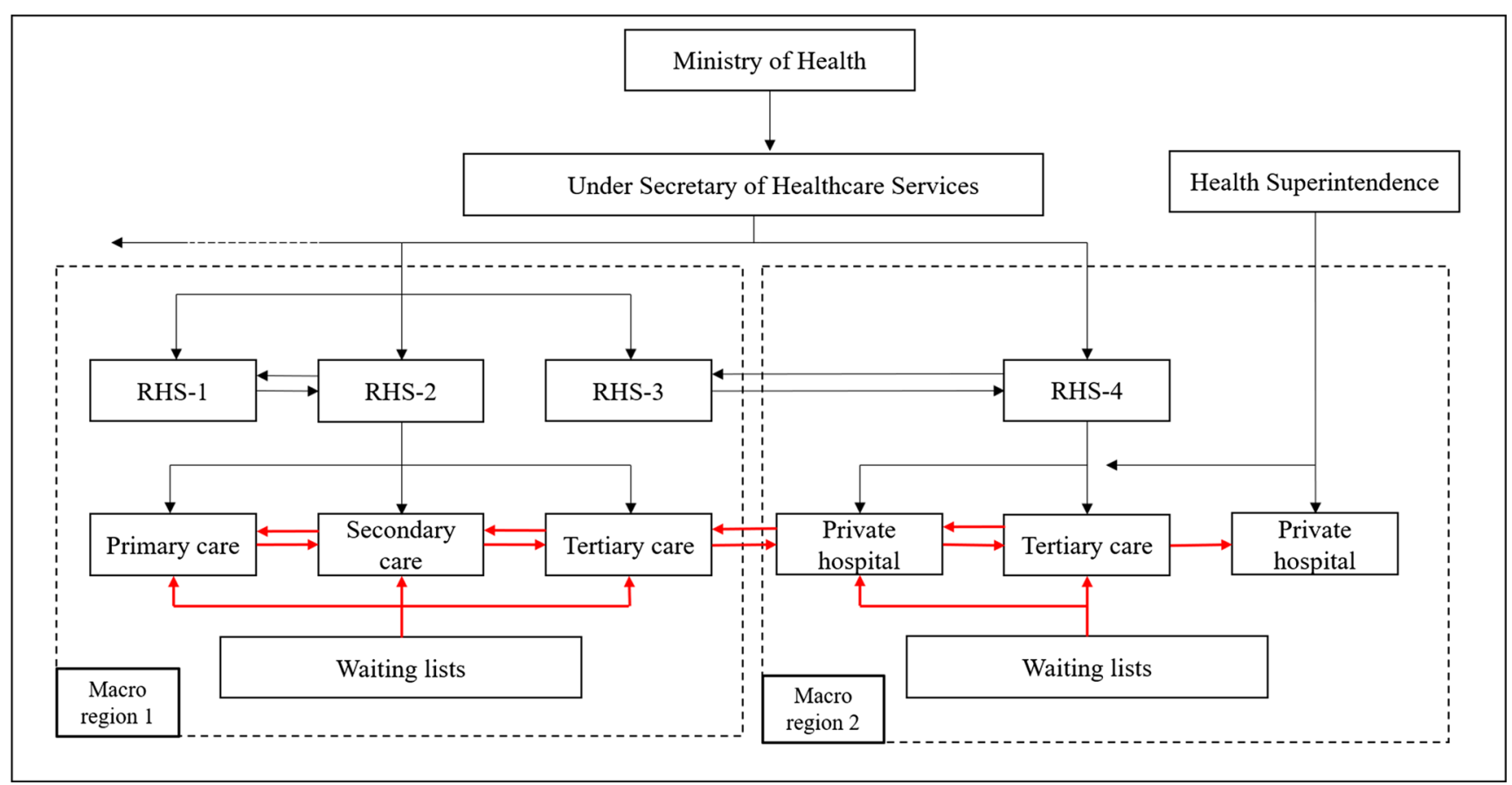

Fig. 1 Chilean health system interactions. Abbreviations: RHS = Regional Health Service

a set of consecutive games and optimization problems with different hierarchies to represent how decisions are made and influence themselves. For example, local agreements can impact regional trades or the relationship with private providers, thus impacting the feasible set of the regional model. We developed two frameworks with different mathematical phases to represent system interactions among public hospitals, RHSs, and private hospitals.

\section{Mathematical formulation}

We designed two frameworks to model the system, framework A and framework B. The first framework (A) has three phases of decisions-local, regional, and private. The local phase occurs when public hospitals of the same RHS bargain their waiting lists. The regional phase is solved after finding the solution to the local negotiations. It considers the RHS utilities as a function of the hospitals under their supervision; in this case, the bargaining of waiting lists occurs through the different RHSs. In the private phase, private hospitals are involved in helping to clear the remaining waiting lists, after phases one and two as a backup to the system. In the second framework (B), private hospitals are part of the local and regional negotiations instead of being a back-up system. This implies that private hospitals are considered as players in the two bargaining phases but have a different type of utility function compared to public hospitals.
Let $M$ be the exogenous set of patients on waiting lists that could be transferred to another institution to get service. $N$ denotes the set of hospitals in the system that may need to transfer patients and/or are willing to receive patients. Let $H$ represent the set of RHSs under analysis. The set of private hospitals is defined by $L$. Finally, let $P$ represent the set of specialized medical services required by patients. Each patient $z \in M$ is modeled by a triplet $\left(p, w_{z}, i\right)$, where $p$ represents the specialized medical service needed, $w_{z}$ represents the priority code assigned to patient $z$, and $i$ is the hospital where patient $z$ is on the waiting list for a specialized medical service. Every hospital $i \in N$ is also modeled by a triplet $\left(h, c_{i p}, \delta_{i}\right)$, where $h$ represents the RHS that supervises $i, c_{i p}$ is the remaining capacity of hospital $i$ (after assignment to its internal demand) to treat patients with a need for specialty $p$, and $\delta_{i}$ is the selfishness level of hospital $i$. In the literature, selfishness has been used to describe hospital managers' behaviors or greed [61, 62], to define certain health care routing decisions [63], and to describe noncooperative network agents [64]. In our formulation, the exogenous parameter of public selfishness represents the lack of desire to share capacity with other providers due to, for example, compromises of production, the difference in payments based on patients' origin, or concern about future demand. Table 1 summarizes all indices, parameters, and variables required for the mathematical formulations.

Next, we introduce the frameworks' formulation and describe the modification required in each phase. 
Table 1 Indices, parameters, and decision variables of the formulation

\begin{tabular}{|c|c|}
\hline Index & Definition \\
\hline$i$ & Hospital $i$, where $i \in N$ \\
\hline$j$ & Hospital $j$, where $j \in N$ and $j \neq i$ \\
\hline$z$ & Patient $z$, where $z \in M$ \\
\hline$p$ & Specialty $p$, where $p \in P$ \\
\hline$l$ & Private hospital $l$, where $l \in L$ \\
\hline$h$ & Health service $h$, where $h \in H$ \\
\hline Parameter & Definition \\
\hline$w_{z}$ & The priority code assigned to patient $z$ \\
\hline$c_{i p}$ & Remaining capacity of hospital $i$ to treat patients with specialty $p$ \\
\hline$\delta_{i}$ & Selfishness factor of hospital $i$ \\
\hline$\delta_{l}$ & Selfishness factor of private hospital $l$ \\
\hline$\theta_{i h}$ & Utility of hospital $i$ that belongs to health service $\mathrm{h}$ before negotiations (disagreement point) \\
\hline$k_{i h}$ & Binary parameter equal to 1 if hospital $i$ belongs to health service $h$ \\
\hline$s_{i j}$ & Binary parameter equal to 1 if hospitals $i$ and $j$ belong to the same health service \\
\hline$d_{i l}$ & Binary parameter equal to 1 if hospitals $i$ and $l$ belong to the same health service \\
\hline$a_{p l}$ & Available capacity per specialty $p$ at private hospital $l$ \\
\hline$b_{l h}$ & Binary parameter equal to 1 if private hospital i belongs to health service $h$ \\
\hline$\omega$ & Maximum value of priority among all patients \\
\hline$\Psi_{p}$ & Difference in the price paid between public and private network for specialty $p$ \\
\hline$\epsilon$ & A small value to avoid mathematical errors (e.g., $10^{-6}$ ) \\
\hline Variable & Definition \\
\hline$x_{i j p}^{z}$ & 1 if patient $z$ with a need for specialized medical service $p$ that belongs to hospital $i$ is transfered to hospital $j, 0$ otherwise \\
\hline$x_{i l p}^{z}$ & 1 if patient $z$ with a need for specialized medical service $p$ that belongs to hospital $i$ is transfered to private hospital $l, 0$ otherwise \\
\hline$t_{i}$ & Utility of hospital $i$ based on the number of patients transfered to other institutions \\
\hline$y_{i}$ & Utility of hospital $i$ based on the remaining capacity \\
\hline$u_{i h}$ & Total utility of hospital $i$ that belongs to health service $h$ \\
\hline$u_{l h}$ & Total utility of private hospital $l$ that belongs to health service $h$ \\
\hline$\sigma_{l}$ & Total number of patients received by private hospital $l$ \\
\hline$u_{l}$ & Total utility of private hospital $l$ \\
\hline$r_{i}$ & Total utility of hospital $i$ \\
\hline
\end{tabular}

\subsection{General constraints}

The formulation of our two frameworks is based on mixedinteger programming (MIP). To begin we introduce the general constraints. Let $x_{i j p}^{z}$ denote a binary variable that represents patient $z$ with a need for specialized medical service $p$. If the value is equal to one, it indicates that patient $z$ has been transferred from $i$ to $j$ to get specialized medical service; otherwise, it is zero. Constraint (1) represents the fact that a patient can be transferred at most to one new hospital location.

$$
\sum_{i \in N} \sum_{\substack{j \in N \\ j \neq i}} \sum_{p \in P} x_{i j p}^{z} \leq 1 \quad \forall z \in M
$$

Given that each hospital has a limited capacity per medical specialty, constraint (2) ensures that the number of patients being transferred to a given institution does not surpass its capacity.

$\sum_{\substack{j \in N \\ j \neq i}} \sum_{z \in M} x_{j i p}^{z} \leq c_{i p} \quad \forall p \in P \quad \forall i \in N$

Two major elements determine the utility function of each public hospital. The first element is the number of patients on the hospital's waiting lists that is being transferred to other institutions to receive service. The second element is related to the remaining capacity after the negotiations. In Eq. 3, the utility of each public hospital transferring patients to other institutions is presented. The function considers the priority of each patient $w_{z}$ to calculate the total value of each transfer.

$$
t_{i}=\sum_{\substack{j \in N \\ j \neq i}} \sum_{z \in M} \sum_{p \in P} w_{z} x_{i j p}^{z} \quad \forall i \in N
$$


Constraint (4) shows the second element of the utility function. As mentioned, the number of patients received by each hospital through the negotiations reduces the available capacity per specialty for future demand. Therefore, this element decreases the utility as more patients are accepted. The magnitude of the effect over the utility is determined by the level of each institution's selfishness $\delta_{i}$. At the same time, future demand with different priorities could use the slots available for a specialty. Therefore, we considered a unique value common to all patients and institutions, $\omega$. The parameter $\omega$ helps obtain a more robust solution by considering the scenario where the patients in worse condition (highest priority) use the available slots. Consequently, each institution's selfishness $\delta_{i}$ and the highest priority $\omega$ represent the loss of potential gain when sharing an availability instead of keeping it for themselves.

$$
y_{i}=\omega \sum_{p \in P}\left(c_{i p}-\sum_{\substack{j \in N \\ j \neq i}} \sum_{z \in M} x_{j i p}^{z}\right) \delta_{i} \quad \forall i \in N
$$

As a result, constraint (5) combines the elements of constraints (3) and (4) into the total utility function of public hospitals. Binary parameter $k_{i h}$ is equal to 1 if hospital $i$ belongs to RHS $h$ and is 0 otherwise.

$u_{i h}=k_{i h}\left(t_{i}+y_{i}\right) \quad \forall i \in N \quad \forall h \in H$

In Eq. 6, a simpler representation of the utility function of each hospital is introduced.

$r_{i}=\sum_{h \in H} u_{i h} \quad \forall i \in N$

Based on patients' information, constraint (7) fixes the value of some variables as equal to zero.

$x_{i j p}^{z}=0 \quad \forall z \in M \quad \forall i \notin N_{z} \quad \forall p \notin P_{z} \quad \forall j=i \in N$

Constraints (8)-(12) define the range and type of variables used in the models.

$$
\begin{aligned}
& x_{i j p}^{z} \in\{0,1\} \quad \forall i \in N \quad \forall j \neq i \in N \\
& \forall p \in P \quad \forall z \in M \\
& t_{i} \in \mathbb{R}^{+} \quad \forall i \in N \\
& y_{i} \in \mathbb{R}^{+} \quad \forall i \in N \\
& u_{i h} \in \mathbb{R}^{+} \quad \forall i \in N \quad \forall h \in H \\
& r_{i} \in \mathbb{R}^{+} \quad \forall i \in N
\end{aligned}
$$

\subsection{Framework A}

\subsubsection{Phase one (local public negotiations)}

Phase one consists of the local public hospitals' negotiations. As mentioned, the NBS can be used to find a unique Pareto optimal solution to cooperative bargaining, in this case among public hospitals. The maximization of hospitals' utilities through cooperative bargaining is represented by objective function (13). Constraint (14) establishes the axiom of individual rationality; no hospital will accept a payoff (utility) lower than the disagreement point. The status quo or disagreement point $\theta_{i h}$ is calculated based on the utility function (5) of each hospital before negotiations. It becomes evident that the element of Eq. 5 represented by constraint (3) is going to always be zero before bargaining. At the same time, the element represented by constraint (4) can be equal to zero if the selfishness $\delta_{i}$ is zero. Otherwise, it will take the value of the total available capacity multiplied by the maximum priority, $\omega$, and $\delta_{i}$. Given that phase one is restricted to local negotiations, constraint (15) guarantees that no trade takes place outside the RHS.

$\max \prod_{i \in N}\left(r_{i}-\sum_{h \in H} \theta_{i h}\right)$

subject to Eqs. 1-12 and

$$
\begin{aligned}
& r_{i} \geq \sum_{h \in H} \theta_{i h} \quad \forall i \in N \\
& x_{i j p}^{z} \leq s_{i j} \quad \forall i \in N \quad \forall j \neq i \in N \quad \forall p \in P \quad \forall z \in M
\end{aligned}
$$

\subsubsection{Phase two (regional public negotiations)}

Phase two describes the regional public hospitals' negotiations in which RHSs' payoffs are considered. Each RHS's utility is calculated considering the hospitals under its supervision as the difference between the sum of all public hospital utilities minus the sum of all disagreement points. In this way, each RHS's utility becomes a function of individual utilities, where the RHS protects the interest of the institutions under its supervision. The objective function (16) represents the cooperative bargaining among RHSs, while constraint (14) guarantees that no hospital receives a utility lower than its disagreement point. In the regional phase, the solution obtained in the local bargaining helps to define the feasible space of phase two. In other words, the matrix of variables $x_{i j p}^{z}$, the set $M$, the disagreement points of each public hospital $\theta_{i h}$ (depending on capacity), and the remaining capacity per specialty of each hospital $c_{i p}$ are 
updated. Constraint (17) ensures that all hospitals' transfers take place outside their RHS.

$\max \prod_{h \in H} \sum_{i \in N}\left(u_{i h}-\theta_{i h}\right)$

subject to Eqs. 1-12, 14 and

$$
\begin{aligned}
x_{i j p}^{z} \leq 1-s_{i j} \quad \forall i \in N \quad \forall j \neq i & \\
& \forall p \in P \quad \forall z \in M
\end{aligned}
$$

\subsubsection{Phase three (private hospitals as a back-up)}

Phase three considers the decisions after local and regional negotiations have used all available public resources. The idea behind this level of analysis is to measure the financial impact of using private hospitals as a back-up system to help clear the remaining waiting lists. Therefore, as well as in the regional phase, the matrix of variables $x_{i j p}^{z}$ and the set $M$ are updated based on the previous phase solution. Phase three requires the incorporation of the binary variables $x_{i l p}^{z}$; similar to $x_{i j p}^{z}, x_{i l p}^{z}$ is equal to one if patient $z$ with a need for specialized medical service $p$ from public hospital $i$ is transferred to private hospital $l$ and is equal to zero otherwise. This multi-objective model of two functions (biobjective) generates a nondominated frontier representing the trade-off between minimizing the number of patients on waiting lists, objective function (19), and minimizing the additional cost of serving patients in the private system, objective function (18). The formulation does not include a selfishness term because the back-up role is financially driven and does not conflict with the private providers' profit maximization goal.

Similar to constraint (3), and (20) calculates the utility of transferring patients to private hospitals acknowledging their priority. In Eq. 21, the additional cost of utilizing the private system is calculated. $\Psi_{p}$ represents the difference between the price paid in the private network and the price paid in the public system for the same specialized medical service $p$. Through constraint (22), we consider the fact that patients are transferred to private hospitals.

$$
\begin{aligned}
& \min \sum_{l \in L} u_{l} \\
& \min \sum_{z \in M} w_{z}-\sum_{i \in N} t_{i}
\end{aligned}
$$

subject to Eqs. 1, 9 and

$\begin{aligned} t_{i} & =\sum_{l \in L} \sum_{z \in M} \sum_{p \in P} w_{z} x_{i l p}^{z} \quad \forall i \in N \\ u_{l} & =\sum_{i \in N} \sum_{z \in M} \sum_{p \in P} x_{i l p}^{z} \Psi_{p} \quad \forall l \in L\end{aligned}$

$x_{i l p}^{z} \in\{0,1\} \quad \forall i \in N \quad \forall l \in L \quad \forall p \in P \quad \forall z \in M$
Next, we present framework B, which is independent of the three phases already described. Framework B considers phases in which private hospitals are not a back-up for the public system. Instead, they become active participants in the local and regional negotiations.

\subsection{Framework B}

\subsubsection{Phase one (local negotiations)}

Phase one of framework B presents the first local negotiations in which private hospitals become part of the bargaining. This model uses the NBS to solve the cooperative bargaining problem and considers a new utility function for private hospitals. As can be observed in the objective function (23), most of the equation is equivalent to the model presented in phase one of framework A, except for the new term of private utilities $u_{l h}$. Constraint (24) captures the total number of patients being received by each private hospital with their respective priorities $w_{z}$. This variable, $\sigma_{l}$, is used by constraint (25) to generate a concave utility function for each private institution. The private selfishness term $\delta_{l}$ combined with the available capacity per specialized service $a_{p l}$ determines the maximum value attainable for the concave function. This implies the existence of a point after which private hospitals lose utility for receiving patients from the public system. Defining a concave utility function for private hospitals is consistent with realities in which private insurers pay more for service to providers than public insurers. In Eq. 25, $\epsilon$ represents a small number to avoid numerical issues when $\delta_{l}$ is equal to one. In our case, we chose an $\epsilon$ of $10^{-6}$ to avoid changes in the value of $u_{l h}$ when $\delta_{l}$ is different than one. Constraint (26) guarantees that no hospital negotiates outside its RHS.

$\max \left(\prod_{i \in N}\left(r_{i}-\sum_{h \in H} \theta_{i h}\right)\right)\left(\prod_{l \in L} \sum_{h \in H} u_{l h}\right)$

subject to Eqs. 1-12, 14, 15, 22 and

$\sigma_{l}=\sum_{i \in N} \sum_{z \in M} \sum_{p \in P} x_{i l p}^{z} \quad \forall l \in L$

$u_{l h}=b_{l h}\left(-\frac{1}{\left(1+\epsilon-\delta_{l}\right) a_{p l}}\left(\sigma_{l}\right)^{2}\right.$

$$
\left.+2\left(\sigma_{l}\right)\right) \quad \forall l \in L \quad \forall h \in H
$$

$x_{i l p}^{z} \leq d_{i l} \quad \forall i \in N \quad \forall l \in L \quad \forall p \in P \quad \forall z \in M$

\subsubsection{Phase two (regional negotiations)}

Phase two of framework B describes the negotiations among public and private providers that take place at the regional level. Like in phase one, the private hospitals are included 
in the objective function (27) but in this case are also part of the RHS's objective function. This implies that the social benefit generated by private hospitals is accounted for in the utility function of the RHS. In the regional phase, the solution obtained from the local bargaining helps to define the feasible space of phase two. This means that the matrix of variables $x_{i j p}^{z}$ and $x_{i l p}^{z}$, the set $M$, the remaining capacity per specialty of each hospital $c_{i p}$ and $a_{p l}$, and the disagreement points of each public hospital $\theta_{i h}$ are updated. Constraint (28) guarantees that patients can only be transferred to private hospitals outside their RHS.

$\max \prod_{h \in H}\left(\sum_{i \in N}\left(u_{i h}-\theta_{i h}\right)+\sum_{l \in L} u_{l h}\right)$

subject to Eqs. 1-12, 14, 17, 22, 24, 25 and

$x_{i l p}^{z} \leq 1-d_{i l} \quad \forall i \in N \quad \forall l \in L \quad \forall p \in P \quad \forall z \in M$

\subsection{Transformation of the models}

As the NBS presented in phases one and two of both frameworks (A and B) has a non-linear objective function, two possible approaches can be used to solve it. We can either use a non-linear solver or transform it into a secondorder cone problem (SOCP). In general, the latter option has the advantage of being efficiently solved by commercial solvers, such as CPLEX, GUROBI, and XPRESS. As an example, let us consider phase one of framework A with the following general form.

$\max \prod_{i \in N}\left(r_{i}-\sum_{h \in H} \theta_{i h}\right)$

subject to Eqs. 1-12 and

$r_{i} \geq \sum_{h \in H} \theta_{i h} \quad \forall i \in N$

$x_{i j p}^{z} \leq s_{i j} \quad \forall i \in N \quad \forall j \neq i \in N \quad \forall p \in P \quad \forall z \in M$

It was shown in [59] that mathematical problems with the structure presented above can be formulated as a mixedinteger SOCP. To begin, a new non-negative variable $\gamma$ and a geometric constraint are added to the model. To avoid computational issues with the geometric constraint, a set of non-negative variables and constraints replace it. Let $\kappa$ be the smallest integer value such that $2^{\kappa} \geq n p$, where $n p$ represents the number of players in the game. After adding the set of non-negative variables $\gamma$ and $\tau$, phase one of framework A can be reformulated as:

$\max \gamma$

subject to Eqs. 1-12, 14, 15 and

$0 \leq \gamma \leq \Gamma$
$0 \leq \Gamma \leq \sqrt{\tau_{1}^{\kappa-1} \tau_{2}^{\kappa-1}}$

$0 \leq \tau_{j}^{l} \leq \sqrt{\tau_{2 j-1}^{l-1} \tau_{2 j}^{l-1}} \quad \forall j=1, . ., 2^{\kappa-l} \quad \forall l=1, . ., \kappa-1$

$0 \leq \tau_{j}^{0}=r_{j}-\sum_{h \in H} \theta_{j h} \quad \forall j=1, \ldots, n p$

$0 \leq \tau_{j}^{0}=\Gamma \quad \forall j=n p+1, . ., 2^{\kappa}$.

Another issue encountered with nonlinear functions relates to private hospitals. In phases one and two of framework B, the utility function is defined as a concave function of patients being received and their priorities. A common practice to deal with concave or convex functions is to use a piecewise linear function to represent it. The advantage of implementing a piecewise linear function is that advanced mixedinteger linear programming techniques can be applied. However, using an approximation in the original function requires checking that the estimate is close enough to the original point $[65,66]$. An example of a piecewise linear approach for a concave function is depicted in Fig. 2. To generate line segments that approximate the function in constraint (25), we use the following general equation.

$L_{x_{0}}=f\left(x_{0}\right)+f^{\prime}\left(x_{0}\right)\left(x-x_{0}\right)$

In Eq. 25, $f\left(x_{0}\right)$ is represented by $u_{l h}$ evaluated in the point $x_{0}$, while $f^{\prime}\left(x_{0}\right)$ is the derivative of $f\left(x_{0}\right)$ with respect to $\sigma_{l}$ evaluated in $x_{0}$. Consequently, the concave private hospitals' utilities become a set of lines where every value of $\sigma_{l}$ can generate a segment.

\section{Case study}

This section presents a case study based on the Chilean scenario. Data was collected from de-identified and publicly

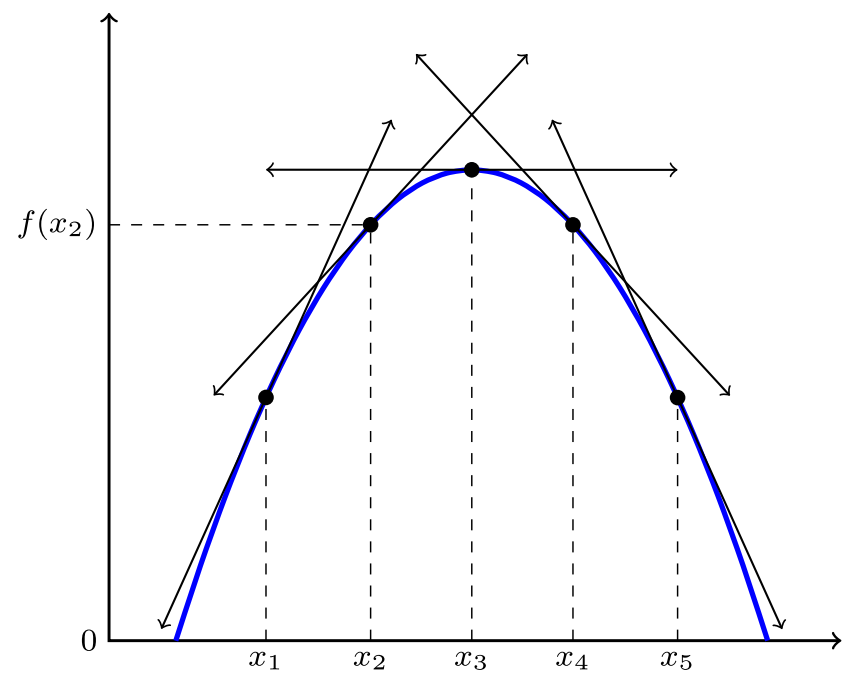

Fig. 2 Example of a piecewise linear concave function built using five linear equations 
available (by request) waiting list databases from separate RHSs-Atacama, Valparaiso-San Antonio, and Osorno [67]. These three RHSs typify the natural divisions of the country, being located in the north, center, and south of Chile, respectively. The dataset includes information about patients on waiting lists for non-prioritized specialized medical services from 2008 to 2018 at 77 public medical centers providing primary, secondary, and tertiary levels of care. A total of 35 specialties are included, and four levels of priorities (low, moderate, considerate, and high) were estimated. The priority code is an outcomes-driven estimation of the mortality risk of a patient on a waiting list using the algorithm presented in [15]. Essentially, we estimate the ratio of the hazard rates corresponding to the 35 specialized services in our waiting list cohort. These hazard ratios were adjusted for age, sex, residence, insurance coverage, and level of care. Similar outcome-driven waiting list prioritization schemes are currently used by Chile's Ministry of Health [68]. For more details about the results of hazard ratios, consult Table 3 in Appendix A.

Given that the data for the years 2008 and 2018 were not completely collected, they were not involved in our analysis of demand. Based on the hospitals' historical utilization levels, the available capacity of each public institution was calculated. The demand in 2017 was chosen to be analyzed using our models because it is the most recent. Outliers were removed from the dataset using the interquartile range rule [69].

In an initial exploration, we found that of the 137,516 patients on waiting lists in 2017 among the three RHSs, 23,107 never received medical services or a proper diagnosis. Therefore, we use our models to target the unfulfilled demand of 2017, which has the highest mortality rate in recent years [51]. Figure 3 shows the geographical location of each RHS and their 2017 unmet demand.

Based on meetings the authors held with experts from the Chilean Ministry of Health and their valuable feedback and onsite experience, public hospitals' selfishness was defined as the degree of concern about sharing capacity with other hospitals based on the directors' evaluation system, funding mechanisms, or compromises of production, that might jeopardize their ability to meet future demand. In essence, this is a system-induced behavior that inhibits proper collaboration. In the case of private hospitals, which are driven by their financial results, selfishness represents the amount of capacity they are willing to share with the public system, given the risk of sacrificing higher payments from patients with private insurance.

The private hospitals' available capacity for phases one and two of framework $B$ was estimated based on the $46 \%$ historical participation in the provision of specialized medical services in Chile [70]. For phase three of framework $\mathrm{A}$, the additional cost of serving patients in private hospitals

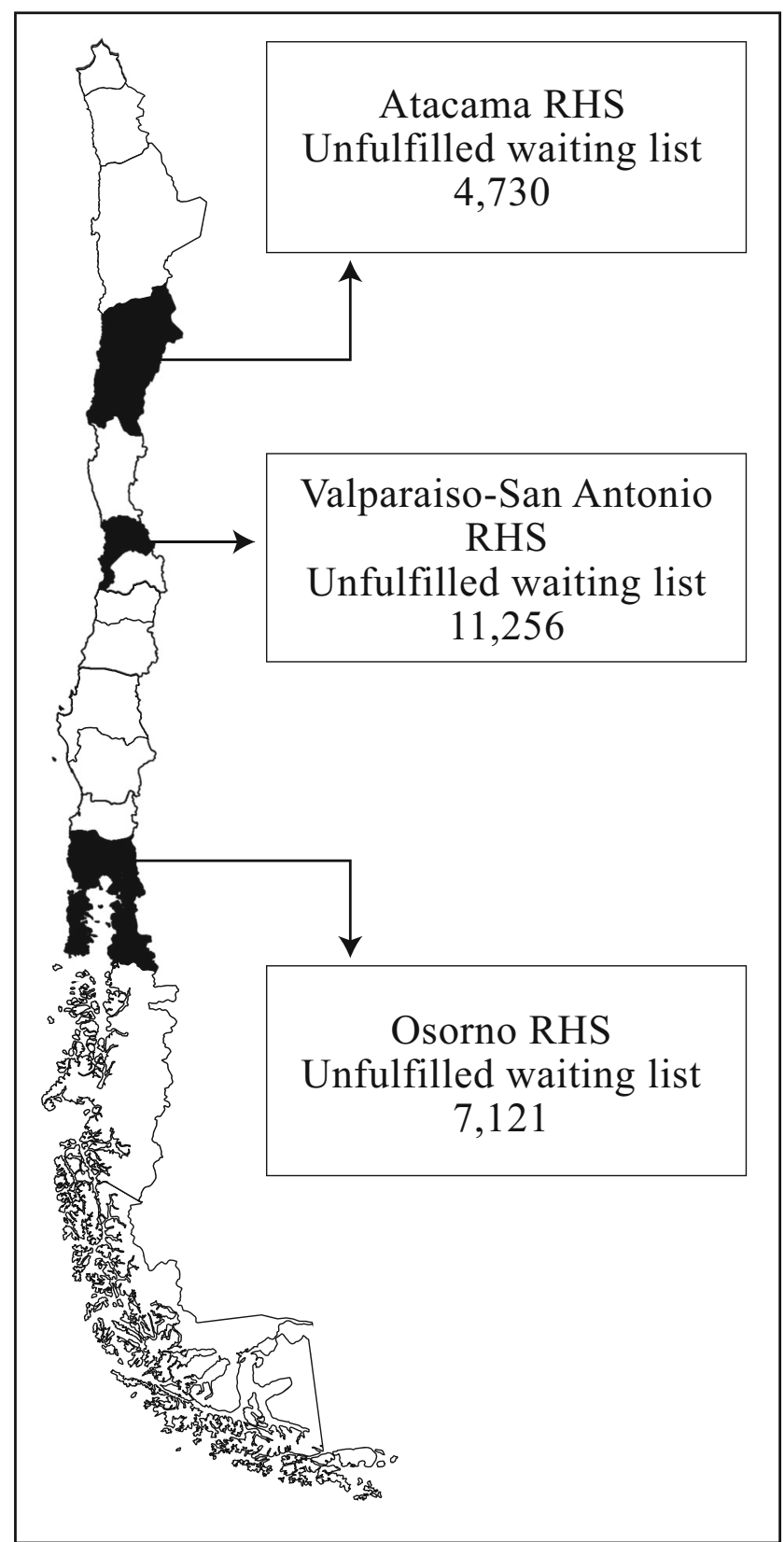

Fig. 3 Unfulfilled waiting lists per the selected RHSs. Abbreviations: RHS $=$ Regional Health Service

was calculated from the difference in the appointment price per medical specialty between the public system [71] and a private hospital in Santiago (capital of Chile) [72]. The second column in Table 2 presents the additional cost per specialty of diagnosing one patient in the private network.

\section{Results}

This section provides the results of the case study evaluated in our two frameworks. The MIP phases were implemented 
Table 2 Framework A input data and results for phases I and II with zero selfishness

\begin{tabular}{|c|c|c|c|c|c|c|c|c|c|c|}
\hline \multirow[t]{2}{*}{ Specialty } & \multirow[t]{2}{*}{ Additional $\operatorname{cost}^{1}$} & \multirow[t]{2}{*}{ Demand $^{2}$} & \multirow[t]{2}{*}{ Capacity $^{2}$} & \multicolumn{2}{|c|}{ Atcama } & \multicolumn{2}{|c|}{ Valparaiso $^{3}$} & \multicolumn{2}{|c|}{ Osorno } & \multirow[t]{2}{*}{ Total PH I \& II } \\
\hline & & & & PH I & PH II & PH I & PH II & PH I & PH II & \\
\hline Adult SX & 18 & 80 & 14 & 0 & 0 & 1 & 13 & 0 & 0 & 14 \\
\hline Anesthesiology & 18 & 24 & 1 & 0 & 0 & 1 & 0 & 0 & 0 & 1 \\
\hline Breast SX & 18 & 0 & 23 & 0 & 0 & 0 & 0 & 0 & 0 & 0 \\
\hline Bronchopulmonary & 0 & 15 & 19 & 0 & 0 & 9 & 0 & 0 & 6 & 15 \\
\hline Cardiology & 0 & 46 & 26 & 0 & 12 & 14 & 0 & 0 & 0 & 26 \\
\hline Cardiovascular SX & 0 & 14 & 6 & 0 & 0 & 1 & 0 & 0 & 5 & 6 \\
\hline Dentistry & 18 & 525 & 0 & 0 & 0 & 0 & 0 & 0 & 0 & 0 \\
\hline Dermatology & 16 & 15 & 77 & 0 & 0 & 0 & 0 & 0 & 15 & 15 \\
\hline Endocrinology & 0 & 6 & 8 & 0 & 0 & 2 & 0 & 0 & 4 & 6 \\
\hline Family Medicine & 29 & 0 & 3 & 0 & 0 & 0 & 0 & 0 & 0 & 0 \\
\hline Gastroenterology & 0 & 14 & 25 & 3 & 0 & 10 & 1 & 0 & 0 & 14 \\
\hline Genetics & 0 & 4 & 24 & 0 & 0 & 0 & 4 & 0 & 0 & 4 \\
\hline Hematology & 0 & 23 & 2 & 0 & 0 & 2 & 0 & 0 & 0 & 2 \\
\hline Infectious Disease & 0 & 5 & 6 & 0 & 5 & 0 & 0 & 0 & 0 & 5 \\
\hline Internal Medicine & 0 & 60 & 110 & 16 & 0 & 39 & 5 & 0 & 0 & 60 \\
\hline Maxillofacial SX & 0 & 182 & 0 & 0 & 0 & 0 & 0 & 0 & 0 & 0 \\
\hline Nephrology & 10 & 11 & 18 & 0 & 0 & 3 & 0 & 0 & 8 & 11 \\
\hline Neurology & 0 & 86 & 51 & 12 & 0 & 23 & 0 & 0 & 16 & 51 \\
\hline Neurosurgery & 0 & 37 & 22 & 0 & 0 & 13 & 4 & 0 & 5 & 22 \\
\hline Nutrition & 19 & 5 & 4 & 0 & 0 & 4 & 0 & 0 & 0 & 4 \\
\hline Gynecology & 18 & 102 & 231 & 9 & 0 & 28 & 0 & 0 & 65 & 102 \\
\hline Oncology & 0 & 26 & 4 & 0 & 0 & 0 & 4 & 0 & 0 & 4 \\
\hline Ophtalmology & 0 & 483 & 215 & 164 & 0 & 1 & 50 & 0 & 0 & 215 \\
\hline Other & 18 & 1 & 8 & 0 & 0 & 0 & 0 & 0 & 1 & 1 \\
\hline ENT & 16 & 26 & 284 & 6 & 0 & 15 & 5 & 0 & 0 & 26 \\
\hline Pediatrics & 4 & 10 & 27 & 1 & 0 & 0 & 0 & 0 & 9 & 10 \\
\hline Physical Medicine & 10 & 0 & 41 & 0 & 0 & 0 & 0 & 0 & 0 & 0 \\
\hline Plastic SX & 18 & 0 & 5 & 0 & 0 & 0 & 0 & 0 & 0 & 0 \\
\hline Proctological SX & 10 & 33 & 0 & 0 & 0 & 0 & 0 & 0 & 0 & 0 \\
\hline Psychiatry & 7 & 8 & 57 & 0 & 0 & 8 & 0 & 0 & 0 & 8 \\
\hline Rheumatology & 24 & 16 & 0 & 0 & 0 & 0 & 0 & 0 & 0 & 0 \\
\hline Sexual Diseases & 24 & 23 & 5 & 0 & 0 & 0 & 5 & 0 & 0 & 5 \\
\hline Traumatology & 24 & 39 & 169 & 0 & 0 & 0 & 0 & 0 & 39 & 39 \\
\hline Urology & 10 & 53 & 111 & 0 & 0 & 0 & 36 & 0 & 17 & 53 \\
\hline Total & & 1972 & 1596 & 211 & 17 & 174 & 127 & 0 & 190 & 719 \\
\hline$\%$ of Demand & & 100 & 80.93 & 52.36 & 8.9 & 18.1 & 16.1 & 0 & 31.3 & 36.46 \\
\hline
\end{tabular}

Abbreviations: PH, phase; SX, surgery; ENT, ear, nose, and throat; PH I, local transfers; PH II, regional transfers

${ }^{1}$ Additional cost of diagnosis in the private network in US dollars

2 Average monthly values

${ }^{3}$ Valparaiso-San Antonio regional health service

in JULIA 1.1.0 and solved using CPLEX 12.9.0. Given the database's size and the complex computational operations, we executed the models considering a monthly demand and capacity. The values were calculated as the average demand and capacity per specialty and medical center. This approach can also be considered as a change in the scale factor of the demand and capacity. Consequently, solving a single month of waiting lists is proportional to solving a full year of demand. Table 2 shows the details of demand and capacity per specialty, where a deficient assignment of resources is observed. For example, maxillofacial surgery has an unfulfilled waiting list of 182 patients per month 
and zero available resources to bargain among the RHSs. However, traumatology has an unfulfilled monthly waiting list of 39 patients but 162 units of capacity available among the RHSs. Despite having a few specialties with zero demand or capacity (making transfers impossible), we included them in our study to generalize the frameworks to the Chilean health system. Moreover, in scenarios with additional RHSs, the unfulfilled demand or underutilized capacity could match new medical centers' needs and resources.

In Fig. 4, the total demand per specialty and their average priority are presented. As can be observed, the two most extensive waiting lists are for ophthalmology and dentistry with a low average priority, which seems reasonable considering that people with low-priority medical needs should wait longer when resources are scarce. However, immediately after these two specialties, the average priority level goes up, implying higher mortality rates.

\subsection{Framework A}

Next, we present the results obtained in the different phases of framework A considering the percentage of demand fulfilled, the transfers per specialty, the impact of public hospitals' selfishness, and private hospitals' role as a backup system.

\subsubsection{Transfers in phases one and two}

Table 2 shows the results per RHS of the local and regional public negotiations (phases one and two, respectively) considering the selfishness factor, $\delta_{i}$, being equal to zero. The last two rows of the table present the total number of patients who received service and the percentage of demand that those transfers fulfilled. As can be observed at the local level, the Atacama and Valparaiso-San Antonio RHSs show a reduction of waiting lists. In contrast, Osorno RHS shows zero transfers upon the local negotiations. This might imply better coordination at the local level in the Osorno RHS, enabling the full utilization of needed resources. In Table 2, we also present the results of regional public negotiations (phase two of the series of games) that take place after the local bargaining considering the remaining demand and capacity (updated feasible space). In this case, all RHSs show a reduction of waiting lists. The most significant improvement occurs in the Osorno RHS with $31.3 \%$ of demand being satisfied, equivalent to 190 patients receiving medical service. In contrasting phases one and two, we observe that the Atacama RHS benefits more from the local negotiations with 211 vs. 17 transfers. In the case of the Valparaiso-San Antonio RHS, the benefits obtained from local and regional bargaining are similar with 174 and 127 transfers, respectively. We already saw

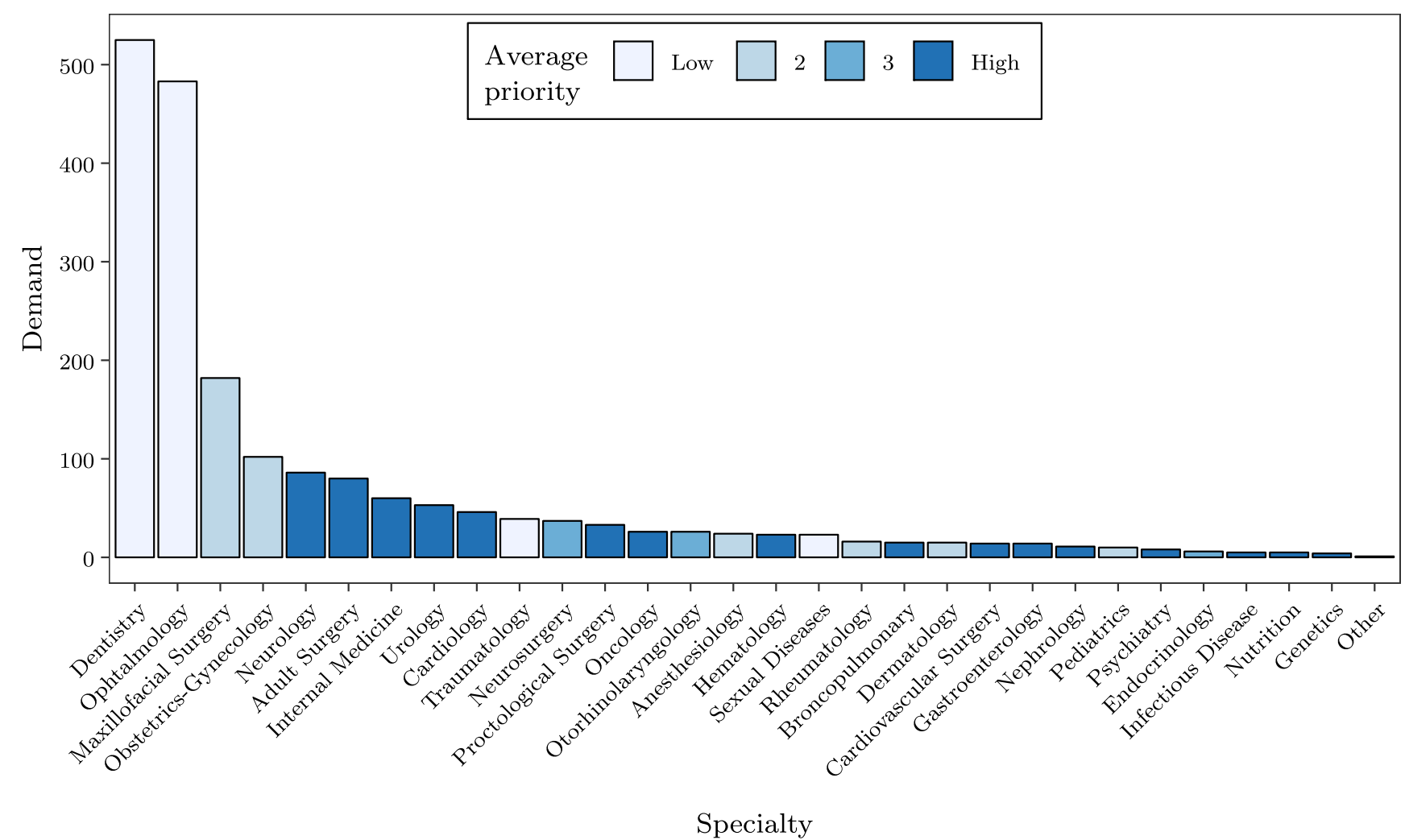

Fig. 4 Total monthly demand per specialty with average priority 
that local negotiations have a greater impact on reducing waiting lists than regional bargaining for the Atacama RHS. However, the number of transfers per medical specialty show that the few regional transfers are for cardiology and infectious diseases, two high-priority (mortality) specialties. In contrast, the largest number of transfers at the local level is in ophthalmology, a low-priority specialty. In the Valparaiso-San Antonio RHS case, the number of patients getting service per specialty at the local and regional level is similar. Nevertheless, local bargaining serves patients with higher priorities, such as neurology, gynecology, and internal medicine. In the regional negotiations, the most significant transfer occurs in ophthalmology, which is the specialty with the smallest number of patients served in the local phase. Osorno RHS only shows regional transfers with a combination of priority levels, such as gynecology (medium-high), traumatology (low), and urology (high). In Table 2, the last column aggregates the number of patients served per specialty due to phases one and two of framework $\mathrm{A}$, considering $\delta_{i}$ is equal to zero.

\subsubsection{Public selfishness}

The main goal of our study is to reduce waiting lists by improving providers' synergy through enhancing interaction structures. Accordingly, the impact of different scenarios of selfishness needs to be examined. Given that the results presented so far have focused on the best possible scenario for public negotiations, selfishness factor $\delta_{i}$ equal to zero, Fig. 5 depicts a sensitivity analysis of $\delta_{i}$ with values ranging between 0 and 1 . This sensitivity analysis shows the impact that public selfishness can have on the number of patients receiving service at the local and regional

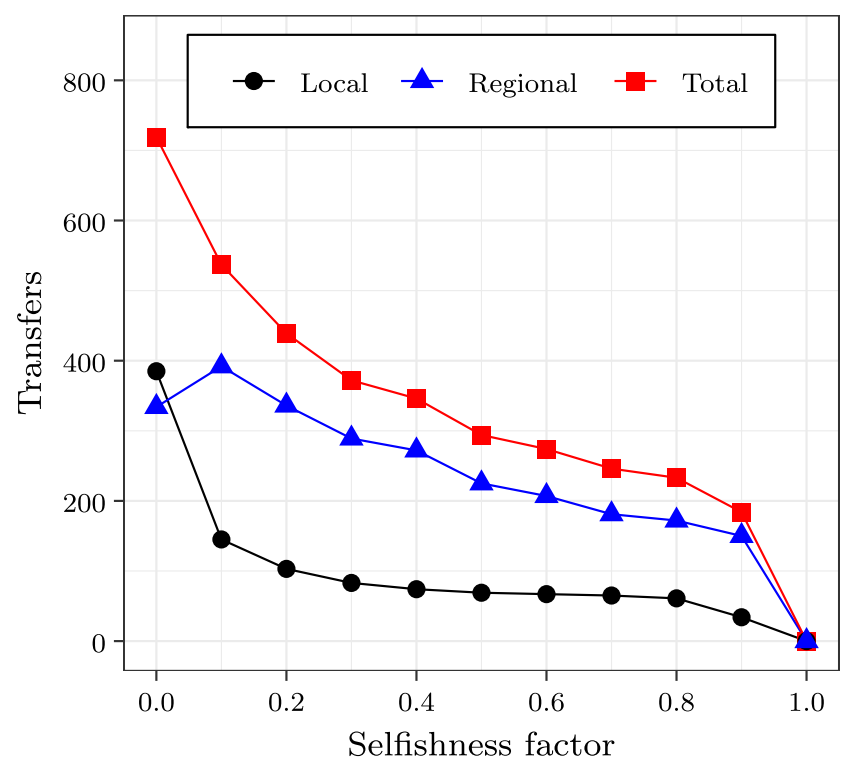

Fig. 5 Impact of selfishness on public interactions levels. The first outcome that can be observed in Fig. 5 is the quick decrease in transfers with local negotiations and the small increase in regional transfers when the value of $\delta_{i}$ starts to increase. This can be explained considering the limited alternatives to negotiate at the local level. As selfishness starts to grow in the system, certain providers could run out of options locally to negotiate, for example, an RHS where only two hospitals provide service for a given specialty. This implies that fewer resources are used in the local negotiations that can be bargained at the regional level, where by default there is a higher number of negotiating providers. The growth of selfishness among public hospitals is related to the capacity being offered, which translates into a deterioration in performance that can jeopardize the reduction of waiting lists to the point of complete stagnation (selfishness equal to one) of negotiations.

The second outcome of the sensitivity analysis of our framework refers to the importance of having a good prioritization system combined with allocation strategies. Figure 6 shows the impact that selfishness has on the number of patients receiving service per priority. As can be observed, the priority curves decay in the same order as their importance. Despite having the highest demand and one of the largest numbers of patients being served, low-priority specialties are first in decay after selfishness starts to increase. In contrast, medical services of high and considerable priority last longer in the system, guaranteeing proper utilization of resources for all scenarios.

\subsubsection{Private hospitals as a back-up system}

In Table 2 column two shows the additional cost (beyond the public expense) per medical specialty of providing an

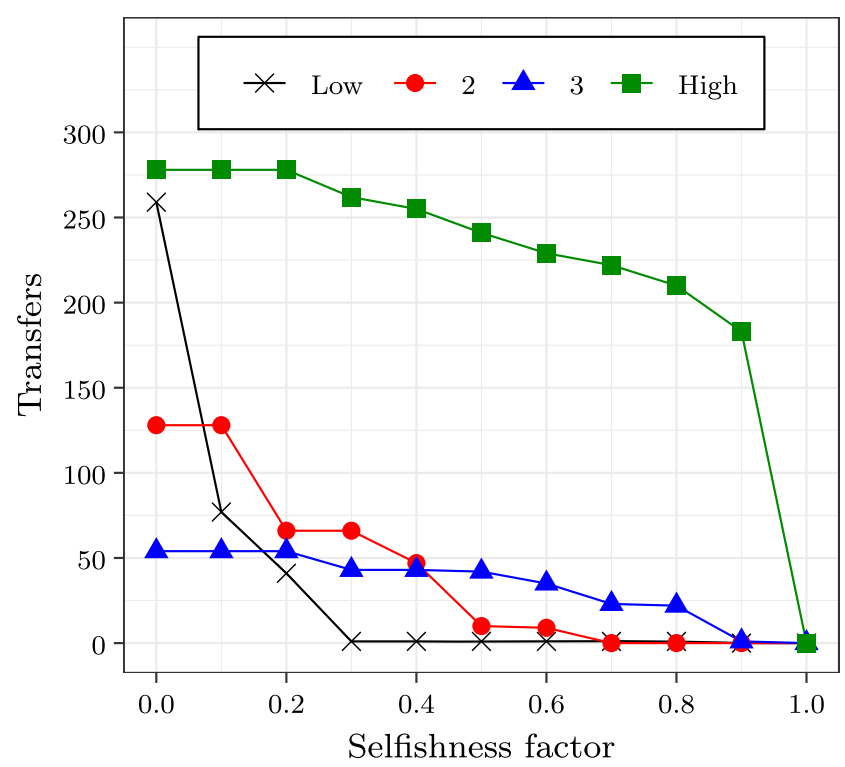

Fig. 6 Impact of selfishness per priority level in public interactions 
appointment for a single patient at a private hospital. The bi-objective model, phase three, generates a nondominated frontier of solutions between the unfulfilled demand and the additional expense needed to diagnose the unserved patients in the private network. In Fig. 7, the trade-off between unfulfilled demand (y-axis) and additional expense (x-axis) is shown. As explained in the preliminaries, the improvement of one objective function can only be obtained by the deterioration of the other objective function. Therefore, every point in the nondominated frontier is an optimal solution that the decision maker can choose based on the available resources or desired fulfillment of demand. Figure 7 highlights the point $(5809,350)$ at which the value in the $\mathrm{x}$-axis is the median of the additional expense curve; however, any point in the curve can be considered for analysis and selected by the decision maker.

Figures 8 and 9 present the number of transfers to the private network per specialty when the chosen solution is the above-mentioned point $(5809,350)$. In Fig. 8, the color of the columns is determined by the additional cost of the medical specialties. It can be seen that most of the columns have light colors, indicating a system preference for specialties with a low additional cost. In contrast, the color of the columns in Figure 9 changes based on the average priority of each specialty. In this case, most of the columns are darker than in Fig. 8, indicating a preference for specialties with high priority. Despite the inclination for high-priority specialties, the first two columns of Fig. 9 are low priority. This can be explained, considering that most of the high-priority patients have already been served in phases one and two.

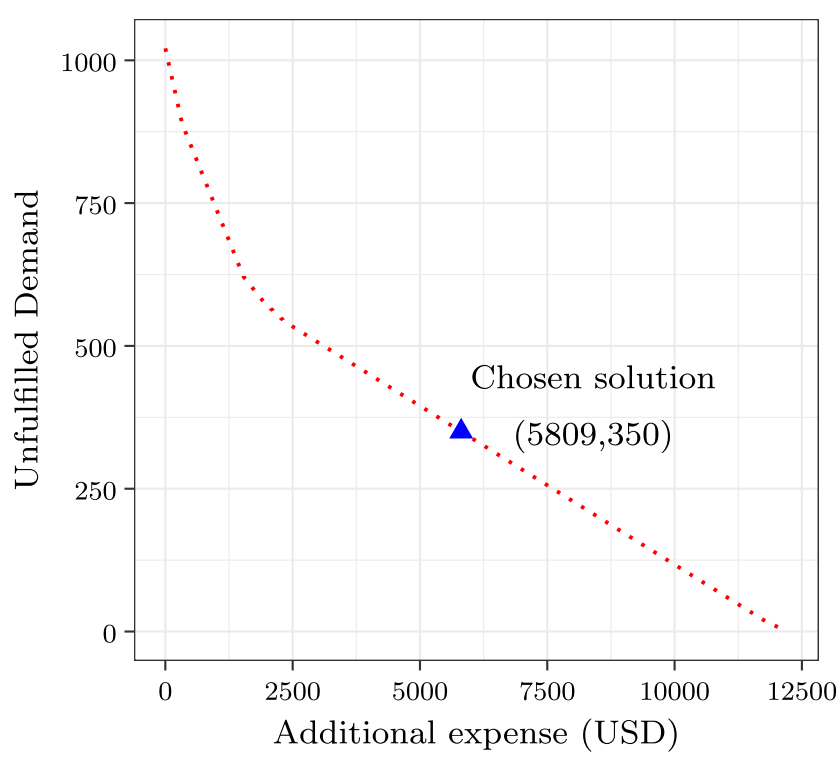

Fig. 7 Nondominated frontier, trade-off between unfulfilled demand and additional expense

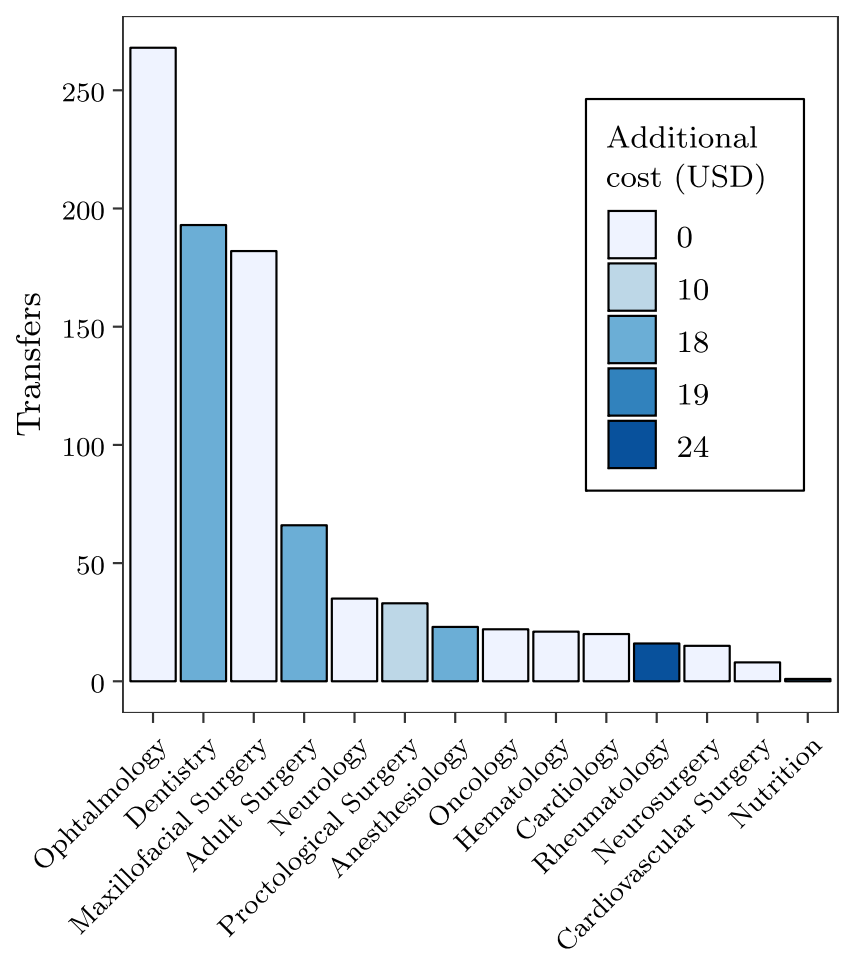

Specialty

Fig. 8 Number of transfers to private network per specialty and additional cost

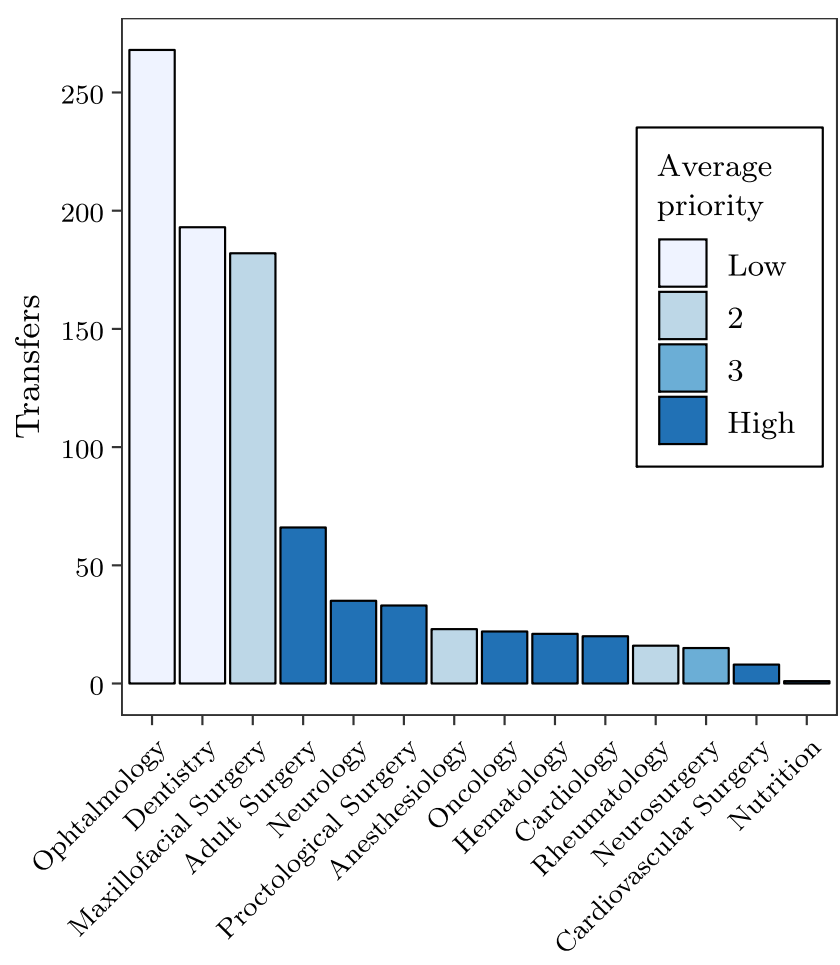

Specialty

Fig. 9 Number of transfers to private network per specialty and priority 


\subsection{Framework B}

Next, we present the results obtained from the local and regional phases of framework B. Figures 10 and 11 show a sensitivity analysis of the public and private selfishness conducted for phases one and two, respectively. In these formulations, the private hospitals are not a back-up system. Rather, they become players that actively participate in the local and regional negotiations. To deal with the private providers' concave utility function, we used a piecewise function that consists of five linear pieces that produced an objective value variation of $10^{-3}$ with respect to four linear pieces, which is negligible considering the range of objective values obtained. Figure 12 summarizes the impact of selfishness on the system and presents the total number of transfers in framework B.

\subsubsection{Selfishness in local and regional negotiations}

In addition to the public network, framework B considers a private setting of three artificial hospitals, one per RHS, with a total of 600 units of combined capacity, approximately $46 \%$ of system participation. We ran 121 models of local and regional negotiations to build the surfaces presented in Figs. 10 and 11. In Fig. 10, the local negotiations are subject to the changes in the factors $\delta_{i}$ (public selfishness) and $\delta_{l}$ (private selfishness) between 0 and 1 . From the generated surface, we observe that public and private selfishness negatively affect the number of patients receiving medical service. However, the reduction related to private selfishness is steadier. This ties to the fact that private hospitals have a different utility function that only considers the patients being received; consequently, the $\delta_{l}$ factor is the single element defining their willingness to negotiate. In the case of public hospitals, a combination of $\delta_{i}$ and the number of patients sent to other hospitals defines the willingness to share. Therefore, as a public provider becomes more selfish, a double negative effect is generated. First, the hospital shares less capacity, thus affecting other institutions. Second, given that other institutions have to reduce their transfer of patients to the selfish hospital, each balance between patients in and out (utility functions) is affected, reducing the capacity sharing of these institutions.

Figure 11 shows the sensitivity analysis for phase two of framework B. When public selfishness increases, the number of transfers is reduced. Conversely, when private selfishness increases, a larger number of patients receive service. Given that the results of the regional phase build upon the results of the local phase, the dependency of Figs. 11 on 10 becomes evident. In local negotiations, if private selfishness increases, the public hospitals are forced to look for resources in the regional bargaining. Conversely, adding private resources to the local network is a good way to avoid regional bargaining in circumstances of high public selfishness.
Fig. 10 Effect of private and public selfishness on local bargaining

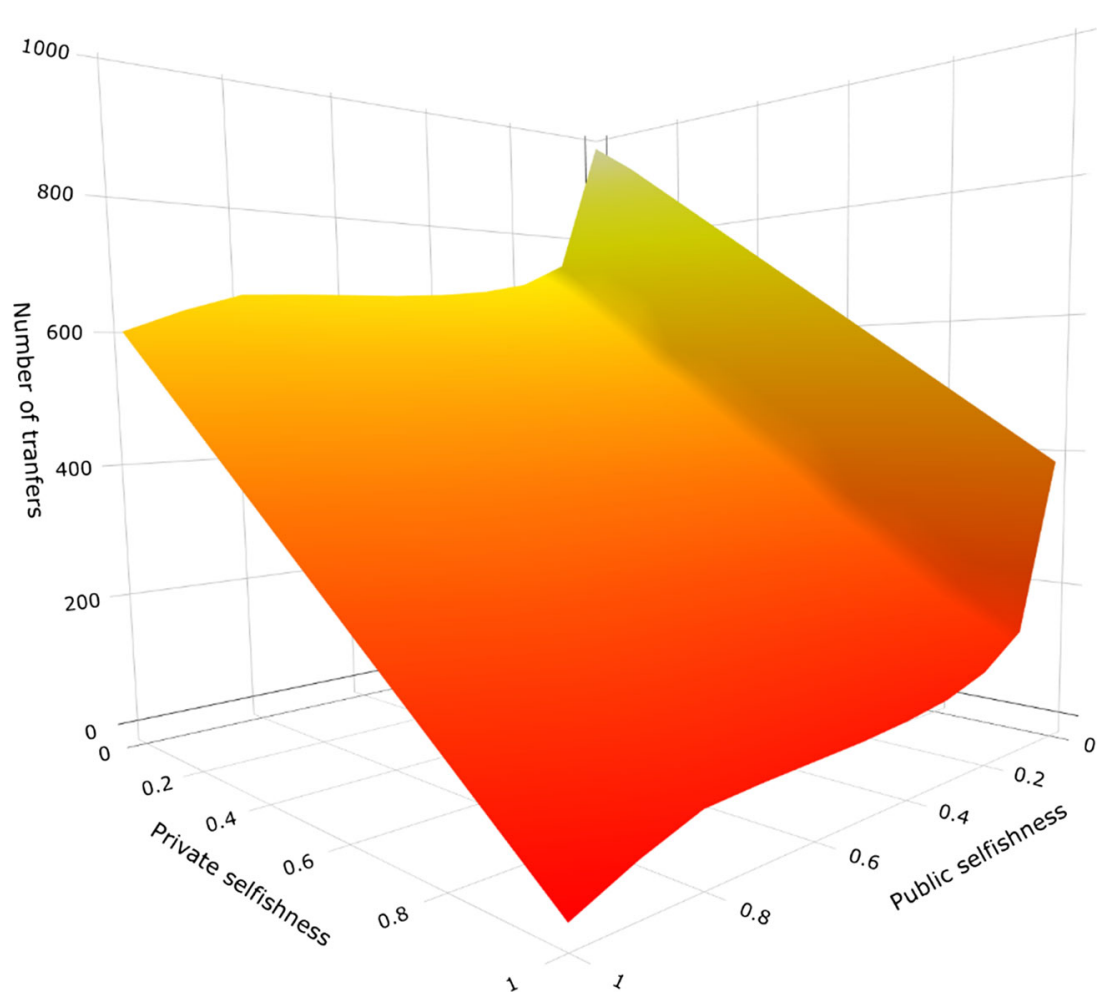


Fig. 11 Effect of private and public selfishness on regional bargaining

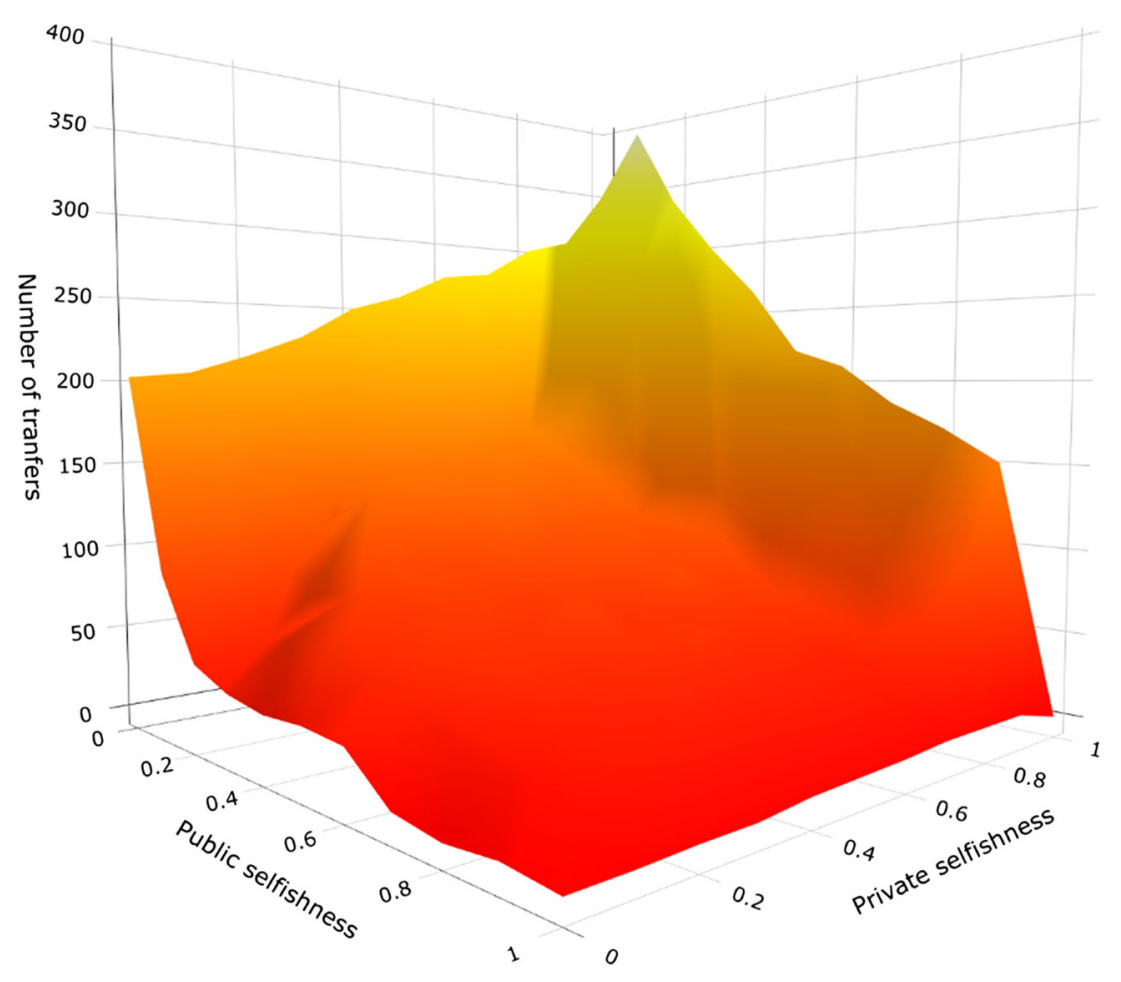

\subsubsection{Transfers in framework B and the selfishness effect}

Figure 12 shows the total impact of the selfishness factors in the reduction of waiting lists. The increase in the values of $\delta_{i}$ or $\delta_{l}$ reduces the number of transfers. Furthermore, it can be seen that public selfishness has a greater impact on the service rate, which can be explained by a combination of factors. First, a larger number of players are affected by public selfishness. Second, the increase in private selfishness generates a small improvement in the regional
Fig. 12 Effect of private and public selfishness on the total number of transfers

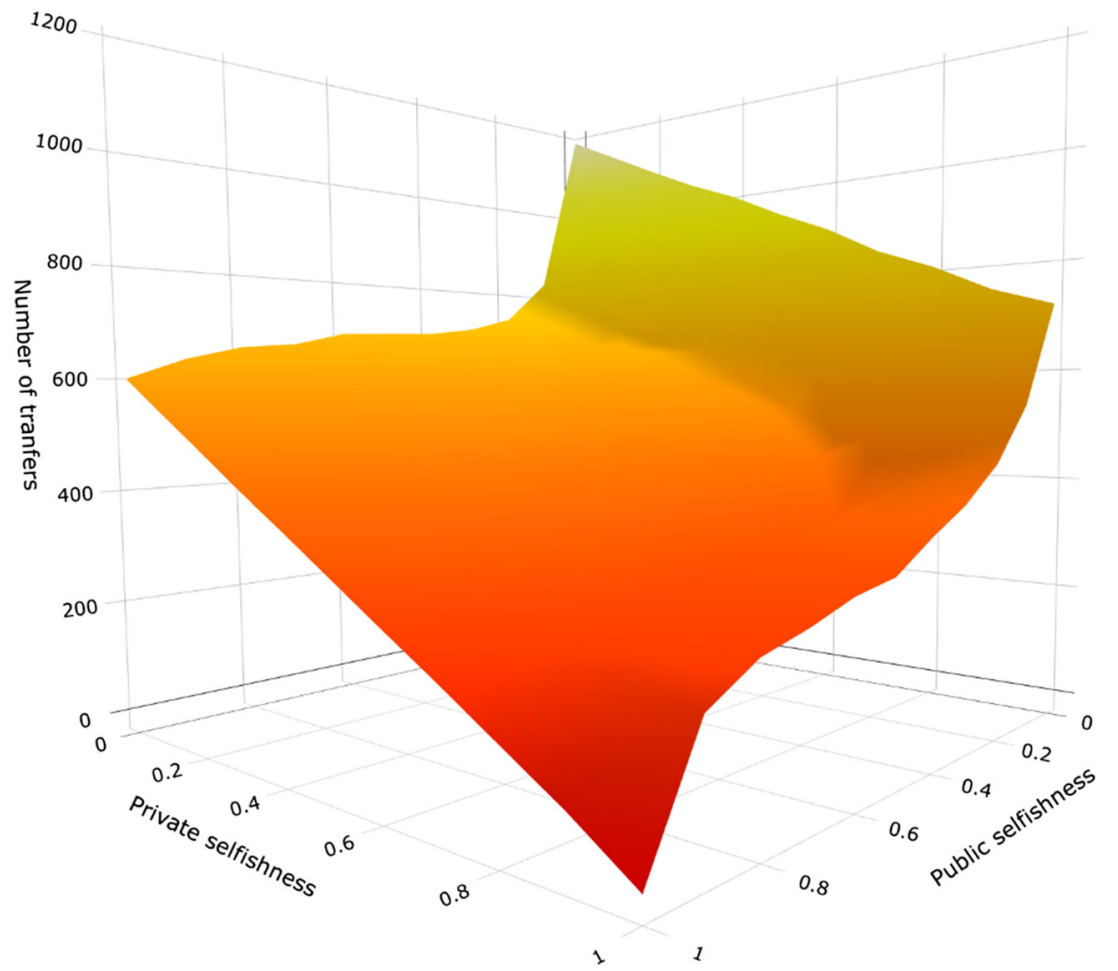


service rate that smoothes its overall negative effect. Finally, public hospitals receive almost double the number of transfers than private hospitals in the best scenario, affecting a more substantial part of the population. In total, framework B was capable of serving 1179 patients when both parameters of selfishness were equal to zero.

\section{Discussion and conclusions}

Increased mortality rates, low quality of life, and public disapproval of governments are some of the consequences of waiting lists for specialized medical services. We propose two frameworks to study system-level mechanisms to reduce waiting lists through consecutive cooperative games and multi-objective optimization. Our models enhance public hospitals' and Regional Health Services' (RHSs) interactions and consider the role that private hospitals might have in the reduction of waiting lists. Additionally, we analyze the impact of selfishness among public and private providers on the health network.

Our case study is based on the Chilean health system where phases one and two of framework A reduced waiting lists, which are not prioritized by the government, by up to $37 \%$ using the available public resources. We also found that each RHS benefits from bargaining in different ways. Osorno benefits only from regional negotiations (phase two) with mixed priorities. This result aligns with recent rankings positioning Osorno RHS in first place for the management and integration of medical centers in its network [73, 74]. Valparaiso-San Antonio reduces waiting lists with both levels of negotiations (phases one and two). However, it is the only RHS benefiting from the trade of patients requiring sexual diseases specialists. This situation might relate to having the largest harbor in the region. Studies have shown that harbors require special attention vis-à-vis sexually transmitted diseases [75, 76]. Atacama benefits from local and regional negotiations but is the only RHS that does not transfer patients to bronchopulmonary specialists. An intuitive explanation relates to the RHS being located in the desert. Studies have shown that meteorological parameters are correlated to respiratory problems [77, 78]. Taken together, these findings highlight the importance of tailored waiting lists designed to satisfy the heterogeneous needs of each region that could be determined by factors such as demographic characteristics, the availability of specialists and equipment, weather conditions, financial resources, and health system management [79-81].

We performed a sensitivity analysis of public selfishness for our framework A, phases one and two. The results show that local negotiations are more sensitive to selfishness and that regional bargaining helps to maintain a higher service rate, even in unfavorable selfish scenarios. However, a prioritization index that ensures patients who are at most risk are at the front of the queue plays a fundamental role in reducing the effect of the system's selfishness. In our models, the prioritization action diverted the negative impact of lack of cooperation toward the low-priority segments.

To reduce the waiting lists even further, we propose two possible roles for private hospitals. In the first (framework A, phase three), private providers act as a back-up system after the public network runs out of medical resources. We found that this approach could generate a set of alternative trade-offs between the additional expense of serving patients in private hospitals and the reduction of waiting lists. According to our cost assumptions, to ensure that each patient in the remaining monthly demand (at selfishness zero) gets to be seen by a physician in the private system, an additional $\$$ US12,000 (beyond what it would cost in the public system) is needed. This translates into a total annual cost of serving remaining patients from the three RHSs in the private network of approximately $\$$ US700,000 (interested readers can find the total private appointment cost per specialty in [72]).

In framework B, private hospitals became players in the local and regional negotiations. Consequently, private and public selfishness could jeopardize the reduction of waiting lists. We found that public selfishness has the worst impact on the system due to the number of players (public hospitals) and the amount of demand (patients) it affects. However, an increase in private selfishness forces public hospitals to look for resources outside their regions, implying higher costs and discomfort for patients. Similar to framework A, regional negotiations are an excellent way to mitigate the negative effect of public selfishness. However, framework B showed that regional negotiations introduce a more significant improvement in private selfishness because public providers can still help each other. By combining public resources and private hospitals' participation as players, framework B reduced the unfulfilled waiting list by up to $60 \%$ when selfishness was equal to zero.

To deal with the selfishness in the health care systems, economic incentives for those helping other institutions or penalties for those not willing to cooperate might prove helpful. Another approach consisting of waiting list credits (total capacity shared) that can be regained in times of need from other institutions can be attractive for providers. A similar approach is utilized in the energy markets where credits can be sold among regions [82].

There are a few points to highlight regarding the applicability of each framework. First, both frameworks can improve public resource utilization, but private hospitals' role will define which approach suits a country's needs better. For example, framework A considers the private providers as a back-up system; consequently, it does 
not require sizable political alignment concerning private providers' participation in the public health system. However, framework A implies a higher expenditure on public health. Framework B requires private providers' involvement as active members in delivering public health care. This can create political and social discomfort in countries with a preference for public health providers, particularly if there is selfishness on the part of private providers. In addition, it requires private providers' willingness to deal with the externalities of providing public goods, and the experience of various countries has shown mixed results regarding private actors participating in the delivery of public care [83].

From a managerial perspective, the number of transfers in our models is equivalent to the system capacity utilization in each framework. Therefore, the sensitivity analysis performed between selfishness and the number of transfers can also be interpreted as the relationship between selfishness and the system capacity utilization (see Appendix B for more details).

Another interesting analysis is comparing our frameworks with a fully centralized assignment model adopting a maximization of the weighted sum of the utility functions. As in our model and given the problem's characteristics (lack of resources in some specialties and excess in others), the centralized model's solution would also allocate all the required/available resources (check Table 2 to see our model's allocation with zero selfishness). However, this method diverges from our solution because the distribution of resources will not align with demand in terms of geographic location. Additionally, it has been shown that centralized models using a weighted sum of functions do not necessarily produce a fair distribution of benefits, and the estimation of weights can be subjective. Conversely, the NBS ensures that the benefits are distributed fairly among the players (hospitals/RHSs) [84]. Interested readers may refer to $[60,85]$ to see the Nash approach's effectiveness in other problems.

Based on the insights derived from our models and data, we believe the Chilean government and its SIGTE have an excellent opportunity to facilitate the local and regional trade of waiting lists among public and private hospitals. For example, to manage the SARS-CoV-2 pandemic, the Chilean government has established a set of instructions to coordinate the public and private networks through the supervision of the Under Secretary of Health Services (see Fig. 1) [86]. However, the design of the SARS-CoV-2 coordinated system could be evaluated or improved with a model such as the one presented in this study. In addition, the Chilean government's efforts to introduce the DRG funding mechanism can also help deal with selfishness due to budgets based on production compromises. As mentioned, private hospitals' support of the public system is subject to each country's internal politics. Opening the public demand equally for private and public hospitals represents a challenge not only from the financial and ethical viewpoints but also from the perspective of quality of care. Given the current inequalities between the public and private health systems in Chile [87], private hospitals' backup role might increase access to a higher quality of care for those in the greatest need without generating a disruptive demand migration.

Our work has some modeling assumptions and data limitations. First, the frameworks require an information system that can frequently provide the status of waiting lists per specialty throughout the country. They also require patient prioritization models that can support the decisions. From the data perspective, our study estimated the priorities using non-clinical patient information, and the additional cost values for private providers were based on the prices of a single private hospital. Additionally, our models do not consider information related to patients' mobility and do not penalize the distance traveled in the regional transfers. In practice, relaxing the last assumptions will imply a reduction in the percentage of improvement. Finally, we assume an absence of uncertainty in relation to the waiting lists; a model considering possible increases in demand due to the improvement in waiting times might be helpful for policymakers. Despite these limitations, our approaches establish strong evidence of how to reduce waiting lists by increasing cooperation. Furthermore, generalizing these frameworks to other countries with and without two-tier health care systems is possible as long as the modeling assumptions are satisfied and the limitations considered.

To our knowledge, this is the first work that combines MIP optimization models with game theory to reduce waiting lists for people requiring specialized medical services. The mathematical frameworks presented in this study provide a quantitative tool for the design of a centralized system to enhance interactions among public and private providers. Policymakers can use the proposed models to determine incentive structures that will promote bargaining for the benefit of patients. Future research that relaxes some of the assumptions and limitations of this work or behavioral studies measuring the selfishness levels might prove helpful.

\section{Appendix A}




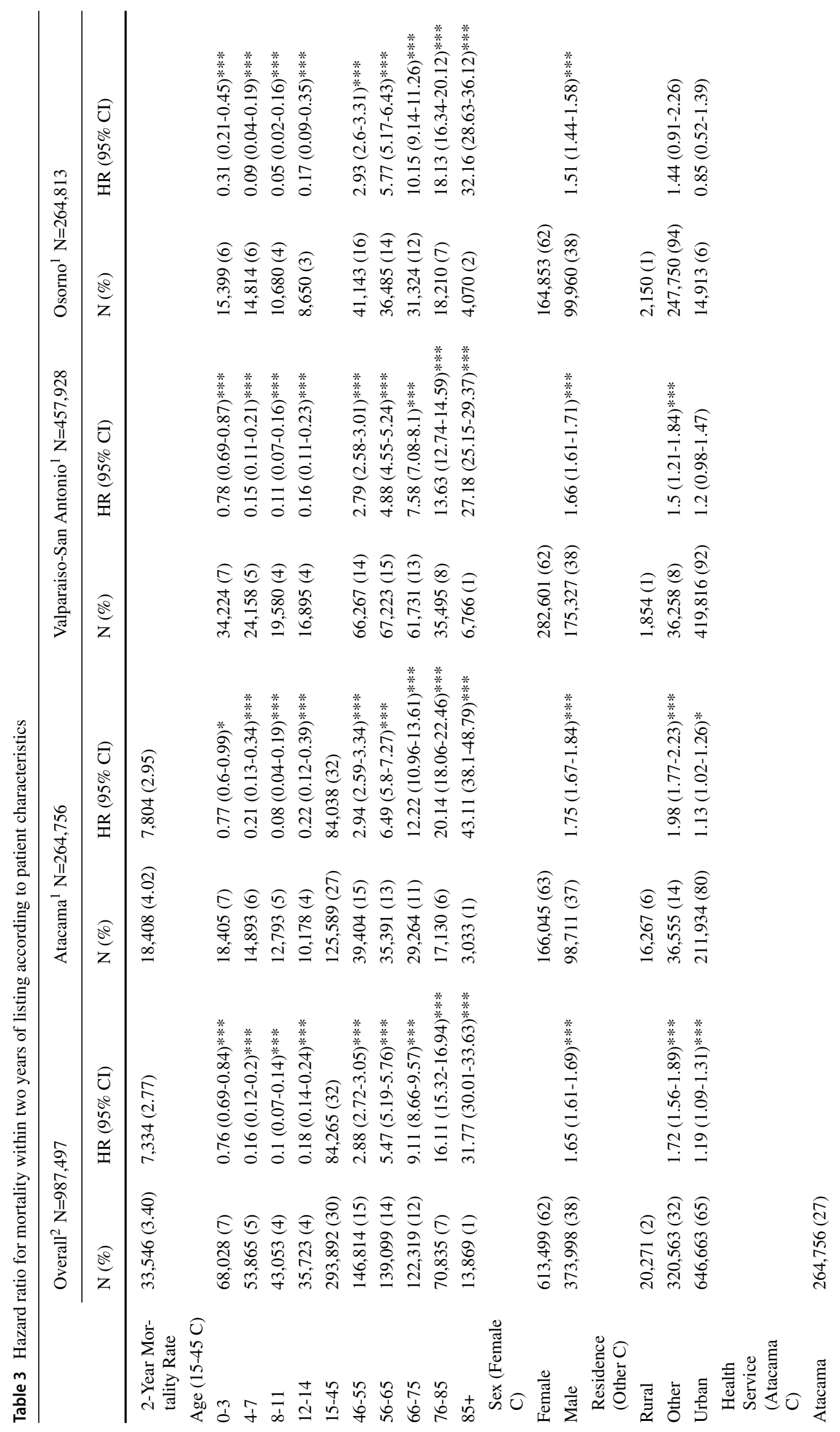




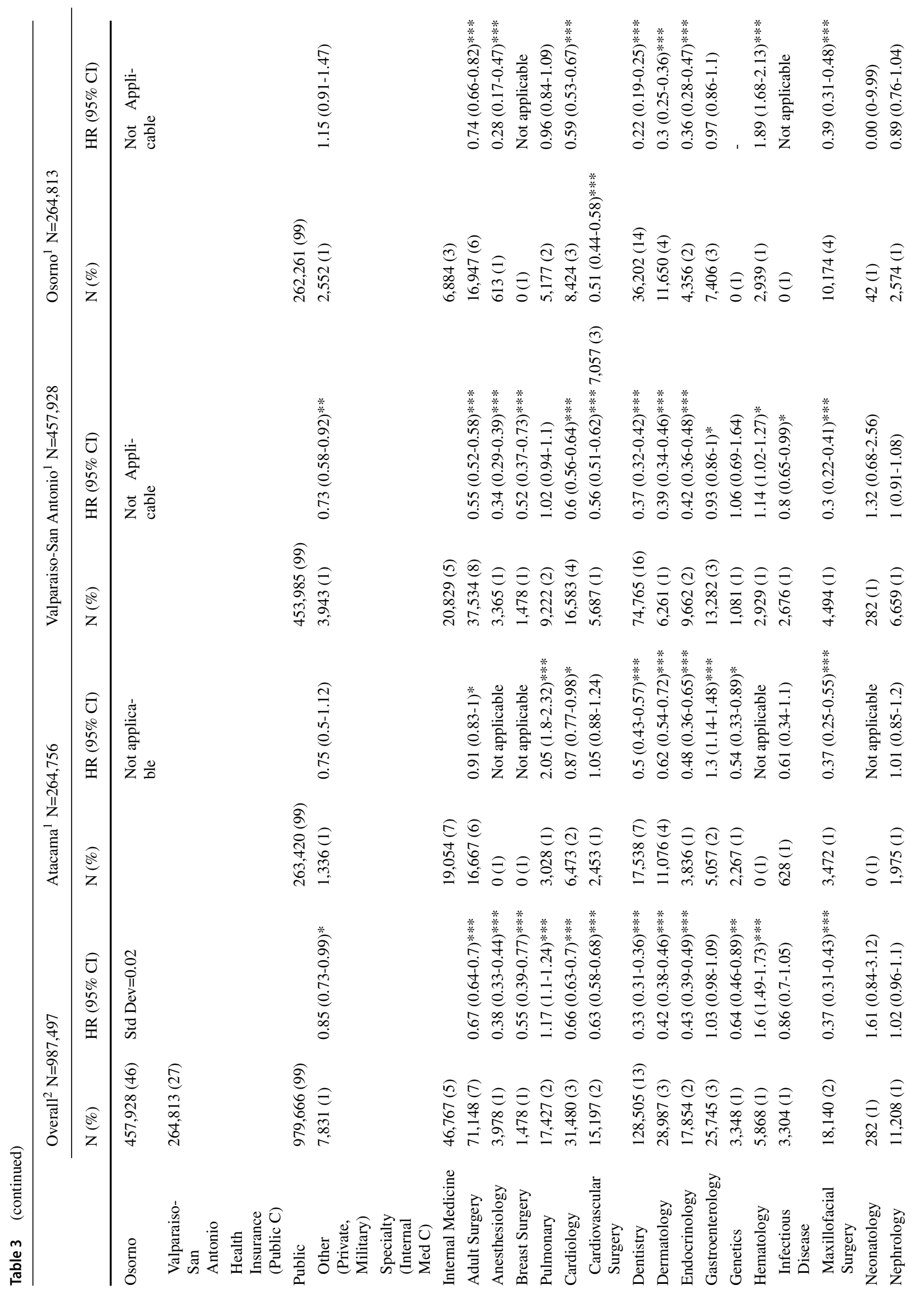




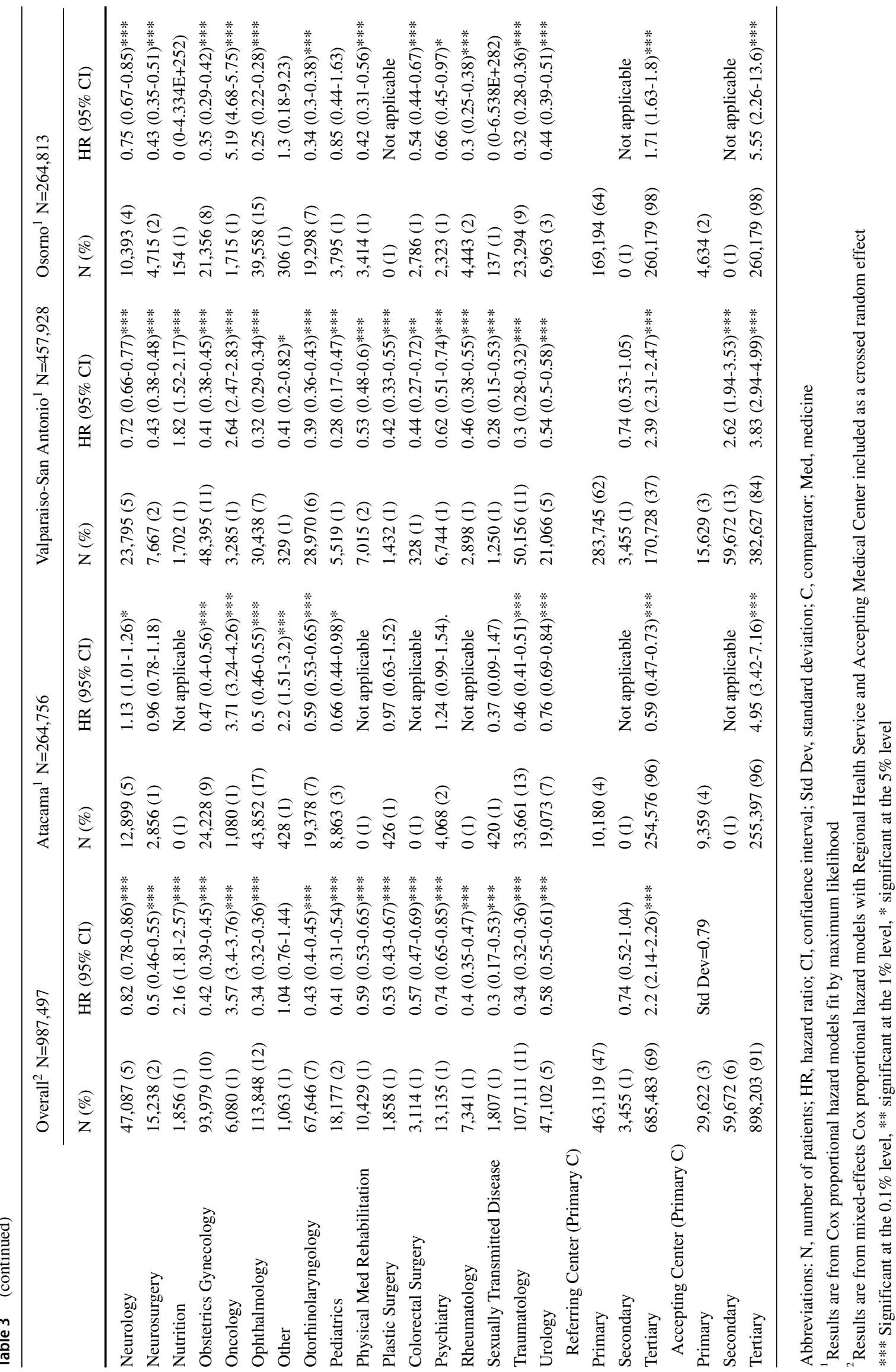




\section{Appendix B}

Here, we provide an example contrasting frameworks A and $\mathrm{B}$ in terms of capacity utilization and selfishness. Given that framework A considers the private providers as a back-up system, it is only affected by public selfishness. Conversely, framework B assumes that private providers are part of the negotiations. Therefore, both types of selfishness are included in framework B. Let us assume as an example that the public and private selfishness are equal to 0.4 . Figures 13 and 14 provide a sensitivity analysis between selfishness, the percentage of capacity utilized, and the number of transfers in each framework. At selfishness of 0.4, framework A serves 346 patients with a $21.7 \%$ capacity utilization, while framework B serves 512 patients with a $23.3 \%$ capacity utilization. Despite the favorable results produced by framework B utilizing public and private capacities, framework A provides similar results using exclusively public resources. Suppose the chosen solution of Fig. 7 is allowed as an additional expenditure to framework A (enabling the backup role of private providers). The number of patients served by framework A will then be 1249, surpassing framework B. Given that framework B can have different combinations of public and private selfishness, Table 4 provides some additional scenarios contrasting selfishness, the number of transfers, and the capacity utilization in this framework.

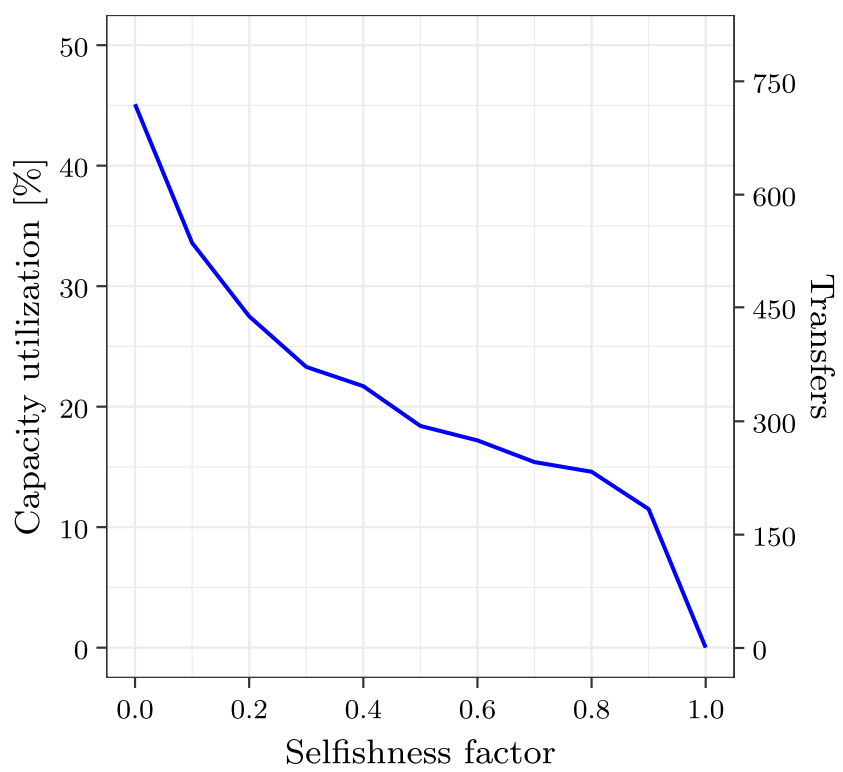

Fig. 13 Impact of public selfishness on the capacity utilization and the number of transfers in framework A

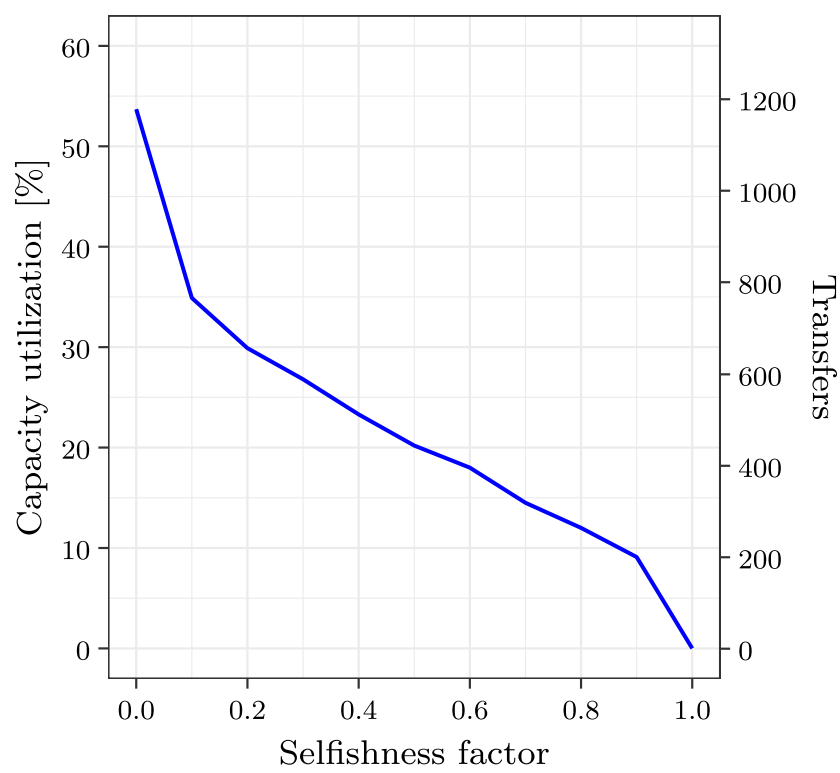

Fig. 14 Impact of selfishness on the capacity utilization and the number of transfers in framework B

Table 4 Examples of the capacity utilization in framework B considering public and private selfishness

\begin{tabular}{|c|c|c|c|}
\hline \multicolumn{2}{|c|}{ Selfishness } & \multicolumn{2}{|c|}{ Framework B } \\
\hline Private & Public & Transfers & $\begin{array}{l}\text { Capacity } \\
\text { utilization (\%) }\end{array}$ \\
\hline 0.0 & 0.0 & 1179 & 53.7 \\
\hline 0.1 & 0.0 & 1130 & 51.5 \\
\hline 0.2 & 0.0 & 1081 & 49.2 \\
\hline 0.8 & 0.1 & 497 & 22.6 \\
\hline 0.9 & 0.1 & 543 & 24.7 \\
\hline 1.0 & 0.1 & 537 & 24.5 \\
\hline 0.5 & 0.3 & 506 & 23.0 \\
\hline 0.6 & 0.3 & 421 & 19.2 \\
\hline 0.7 & 0.3 & 392 & 17.9 \\
\hline 0.4 & 0.4 & 512 & 23.3 \\
\hline 0.5 & 0.4 & 463 & 21.1 \\
\hline 0.6 & 0.4 & 417 & 19.0 \\
\hline 0.0 & 0.5 & 697 & 31.7 \\
\hline 0.1 & 0.5 & 655 & 29.8 \\
\hline 0.2 & 0.5 & 618 & 28.1 \\
\hline 0.8 & 0.6 & 287 & 13.1 \\
\hline 0.9 & 0.6 & 300 & 13.7 \\
\hline 1.0 & 0.6 & 277 & 12.6 \\
\hline 0.5 & 0.7 & 431 & 19.6 \\
\hline 0.6 & 0.7 & 360 & 16.4 \\
\hline 0.7 & 0.7 & 318 & 14.5 \\
\hline
\end{tabular}


Funding Felipe Feijoo was funded by Conicyt MEC 80180112. Diego A. Martinez was partially funded by the Johns Hopkins Health System and the Alliance for a Healthier World. No other funding was provided for this study.

Availability of data and material The waiting lists datasets are publicly available and can be requested from the Chilean government through: https://portaltransparencia.cl/PortalPdT/. The interpretations and reporting of these datasets are the responsibility of the authors and in no way should be seen as an official policy of or interpretation by the medical centers, Regional Health Services, the Ministry of Health of Chile, or the Government of Chile.

\section{Declarations}

Competing interests The authors declare no competing interests.

\section{References}

1. Curtis AJ, Russell CO, Stoelwinder JU et al (2010) Waiting lists and elective surgery: ordering the queue. Med J Aust 192(4):217220. https://doi.org/10.5694/j.1326-5377.2010.tb03482.x

2. Dew K, Cumming J, McLeod D et al (2005) Explicit rationing of elective services: implementing the New Zealand reforms. Health Policy 74(1):1-12. https://doi.org/10.1016/j.healthpol. 2004.12.011

3. Street A, Duckett S (1996) Are waiting lists inevitable? Health Policy 36(1):1-15. https://doi.org/10.1016/0168-8510(95)00790-3

4. McGurran J, Noseworthy $T$ (2002) Improving the management of waiting lists for elective healthcare services: public perspectives on proposed solutions. Hospital Quart 5(3):28-32. https://doi.org/10.12927/hcq.2002.16681

5. Luigi S, Michael B, Valerie M et al (2013) Waiting time policies in the health sector, what works? OECD Publishing. https://doi.org/10.1787/9789264179080-en

6. Morris ME (1924) Voluntary hospitals and poor law infirmaries. Hospital Health Rev 3(29):52. https://www.ncbi.nlm.nih.gov/ pmc/articles/PMC5525673/

7. Paraje G, Vásquez F (2012) Health equity in an unequal country: the use of medical services in Chile. Int J Equity Health 11(1):81. https://doi.org/10.1186/1475-9276-11-81

8. Alves D, Timmins C (2001) Social exclusion and the twotiered healthcare system of Brazil. IDB Working Paper No 148. https://doi.org/10.2139/ssrn.1814695

9. Runnels V, Turner L (2011) Bioethics and transnational medical travel: india, "medical tourism", and the globalisation of healthcare. Indian J Med Ethics 8(1):42-4. https://doi.org/10.20529/ IJME.2011.014

10. Willcox S, Seddon M, Dunn S et al (2007) Measuring and reducing waiting times: a cross-national comparison of strategies. Health Aff 26(4):1078-1087. https://doi.org/10.1377/hlthaff.26. 4.1078

11. Siciliani L, Hurst $\mathbf{J}$ (2005) Tackling excessive waiting times for elective surgery: a comparative analysis of policies in 12 OECD countries. Health Policy 72(2):201-215. https://doi.org/10.1016/ j.healthpol.2004.07.003

12. Collins SR, Davis K, Doty MM et al (2006) Gaps in health insurance: an all-American problem, findings from the Commonwealth Fund Biennial Health Insurance Survey. Commonwealth Fund, pp 14. https://www.commonwealthfund.org/
13. World Health Organization (2015) Tracking universal health coverage: first global monitoring report. World Health Organization. http://apps.who.int/bookorders/anglais/detart1.jsp?codlan=1\& codcol $=93 \& \operatorname{codcch}=329$

14. World Health Organization (2019) Universal health coverage (UHC). https://www.who.int/news-room/fact-sheets/detail/ universal-health-coverage-(uhc)

15. Martinez DA, Zhang H, Bastias M et al (2019) Prolonged wait time is associated with increased mortality for Chilean waiting list patients with non-prioritized conditions. BMC Public Health 19(1):233. https://doi.org/10.1186/s12889-019-6526-6

16. Chalya P, Gilyoma J, Mabula J et al (2011) Incidence, causes and pattern of cancellation of elective surgical operations in a university teaching hospital in the Lake Zone, Tanzania. Afr Health Sci 11(3):438-443. https://www.ajol.info/index.php/ahs/ article/view/73411

17. Koomen EM, Hutten BA, Kelder JC et al (2001) Morbidity and mortality in patients waiting for coronary artery bypass surgery. Eur J Cardiothorac Surg 19(3):260-265. https://doi.org/10.1016/ S1010-7940(01)00580-2

18. Oudhoff J, Timmermans D, Knol D et al (2007) Waiting for elective general surgery: impact on health related quality of life and psychosocial consequences. BMC Publ Health 7(1):164. https://doi.org/10.1186/1471-2458-7-164

19. Ackerman IN, Bennell KL, Osborne RH (2011) Decline in healthrelated quality of life reported by more than half of those waiting for joint replacement surgery: a prospective cohort study. BMC Musculoskelet Disord 12(1):108. https://doi.org/10.1186/14712474-12-108

20. Siciliani L, Moran V, Borowitz M (2014) Measuring and comparing health care waiting times in OECD countries. Health Policy 118(3):292-303. https://doi.org/10.1016/j.healthpol.2014.08.011

21. Stavrunova O, Yerokhin O (2011) An equilibrium model of waiting times for elective surgery in NSW public hospitals. Econ Rec 87(278):384-398. https://doi.org/10.1111/j.1475-4932.2011. 00726.x

22. Vargas V, Poblete S (2008) Health prioritization: the case of Chile. Health Aff 27(3):782-792. https://doi.org/10.1377/hlthaff.27.3. 782

23. Comisión Asesora (2017) Estado de situación personas fallecidas en listas de espera no GES y garantías retrasadas GES. Ministerio de Salud Chile. https://www.minsal.cl/

24. Hanning M (1996) Maximum waiting-time guarantee-an attempt to reduce waiting lists in Sweden. Health Policy 36(1):17-35. https://doi.org/10.1016/0168-8510(95)00791-1

25. Karlberg HI, Brinkmo BM (2009) The unethical focus on access: a study of medical ethics and the waiting-time guarantee. Scand J Public Health 37(2):117-121. https://doi.org/10.1177/ 1403494808101359

26. Viberg N, Forsberg BC, Borowitz M et al (2013) International comparisons of waiting times in health care-limitations and prospects. Health Policy 112(1-2):53-61. https://doi.org/10.1016/ j.healthpol.2013.06.013

27. Jack A (2014) Should healthcare be guaranteed for cancer but not diabetes? BMJ: British Med J 348:g1812. https://doi.org/10.1136/ bmj.g1812

28. Winblad U, Vrangbæk K, Östergren K (2010) Do the waiting-time guarantees in the Scandinavian countries empower patients? International Journal of Public Sector Management. https://doi.org/10.1108/09513551011047242

29. Vissers JM, Van Der Bij JH, Kusters RJ (2001) Towards decision support for waiting lists: an operations management view. Health Care Manag Sci 4(2):133-142. https://doi.org/10.1023/A: 1011409711828 
30. Harding KE, Robertson N, Snowdon DA et al (2018) Are wait lists inevitable in subacute ambulatory and community health services? A qualitative analysis. Aust Health Rev 42(1):93-99. https://doi.org/10.1071/AH16145

31. Cullis JG, Jones PR, Propper C (2000) Waiting lists and medical treatment: analysis and policies. Handb Health Econ 1:12011249. https://doi.org/10.1016/S1574-0064(00)80036-0

32. Knight VA, Williams JE, Reynolds I (2012) Modelling patient choice in healthcare systems: development and application of a discrete event simulation with agent-based decision making. J Simul 6(2):92-102. https://doi.org/10.1057/jos.2011.21

33. Carvalho M, Lodi A, Pedroso JP et al (2017) Nash equilibria in the two-player kidney exchange game. Math Program 161(1-2):389417. https://doi.org/10.1007/s10107-016-1013-7

34. Gladish BP, Parra MA, Terol AB et al (2005) Management of surgical waiting lists through a possibilistic linear multiobjective programming problem. Appl Math Comput 167(1):477-495. https://doi.org/10.1016/j.amc.2004.07.015

35. Stainkey LA, Seidl IA, Johnson AJ et al (2010) The challenge of long waiting lists: how we implemented a GP referral system for non-urgent specialist'appointments at an Australian public hospital. BMC Health Serv Res 10(1):303. https://doi.org/10.1186/1472-6963-10-303

36. Bowers J, Mould G (2002) The deferrable elective patient: a means of reducing waiting-lists in orthopaedics. Journal of Management in Medicine. https://doi.org/10.1108/026892302104348 99

37. González R, Vellasco M, Figueiredo K (2019) Resource optimization for elective surgical procedures using quantuminspired genetic algorithms. Proceedings of the Genetic and Evolutionary Computation Conference, pp 777-786. https://doi.org/10.1145/3321707.3321786

38. Jones E, Lucey C, Wadland L (2000) Triage: a waiting list initiative in a child mental health service. Psychiatr Bull 24(2):5759. https://doi.org/10.1192/pb.24.2.57

39. Gutacker N, Siciliani L, Cookson R (2016) Waiting time prioritisation: evidence from England. Soc Sci Med 159:140-151. https://doi.org/10.1016/j.socscimed.2016.05.007

40. Julio C, Wolff P, Begoña Yarza M (2016) Modelo de gestión de listas de espera centrado en oportunidad y justicia. Rev Méd Chile 144(6):781-787. https://doi.org/10.4067/S003498872016000600014

41. IES (2019) Gasto corriente total en salud, público y privado. Porcentaje del PIB. http://ies.minsal.cl/gastos/sha2011/indicadores/5

42. Subsecretaría de Redes Asistenciales (2018) Sustentabilidad Financiera del Sistema Público de Salud: estableciendo las bases de un nuevo sistema de financiamiento y de gestión. Ministerio de Salud Chile. http://54.148.75.48/handle/123456789/3531

43. OECD (2019) OECD reviews of public health: Chile. OECDiLibrary. https://doi.org/10.1787/9789264309593-en

44. FONASA (2018) Boletin estadistico 2016-2017. http://www. supersalud.gob.cl/664/w3-search.html

45. Alarcon G (2018) Enfrentamiento de tiempos de espera no GES. https://docplayer.es/user/94924829/

46. Letelier LM, Bedregal P (2006) Health reform in Chile. Lancet 368(9554):2197-2198. https://doi.org/10.1016/S01406736(06)69875-9

47. Ministerio de Salud (2018) Garantias explicitas en salud (GES). http://www.supersalud.gob.cl/difusion/665/w3-propertyvalue1962.html

48. Bastías G, Pantoja T, Leisewitz T et al (2008) Health care reform in Chile. Cmaj 179(12):1289-1292. https://doi.org/10.1503/cmaj. 071843

49. Ministerio de Salud (2020) Problemas en salud. https://auge. minsal.cl/problemasdesalud/index
50. Rojas V, Burgos J, Aguilera P et al (2018) Modelo de priorización lista de espera No GES con enfoque de riesgo y tiempos razonables de espera. https://www.minsal.cl/comision-asesora-porlistas-de-espera/

51. Ministerio de Salud (2019) Lista de espera no GES y garantias de oportunidad GES retrasadas 2018. https://www.minsal.cl/ wp-content/uploads/2019/05/Glosa-6-Dic-2018-Finalfallecidosords.pdf

52. INE (2019) Boletin estadisticas vitales problemas en salud. https://www.ine.cl/estadisticas/sociales/demografia-y-vitales/ nacimientos-matrimonios-y-defunciones

53. Castillo-Laborde C, Aguilera-Sanhueza X, Hirmas-Adauy M et al (2017) Health insurance scheme performance and effects on health and health inequalities in Chile. MEDICC Rev 19:57-64. https:// www.scielosp.org/article/medicc/2017.v19n2-3/57-64/en/

54. Barros O, Aguilera I (2013) Asignación de recursos a hospitales: Écómo promover la mejora de servicios y la eficiencia? http://www.dii.uchile.cl/publicaciones/asignacion-de-recursos-ahospitales

55. Dirección de Presupuestos del Ministerio de Hacienda (2019) Informe de finanzas públicas. Tercer trimestre 2019. Gobierno de Chile. https://www.dipres.gob.cl/598/articles-195184_Informe_ PDF_3er_Trimestre.pdf

56. Velasco C (2014) Desafíos y algunos lineamientos para el sistema de seguros de salud en chile. https://www.cepchile.cl/cep/site/ docs/20160304/20160304100905/PPP_003_CVelasco.pdf

57. Ehrgott M (2005) Multicriteria optimization, vol 491. Springer Science \& Business Media. https://www.springer.com/us/book/ 9783540213987

58. Nash Jr J F (1950) The bargaining problem. Econometrica: J Econ Soc 18(2):155-162. https://doi.org/10.2307/1907266

59. Charkhgard H, Savelsbergh M, Talebian M (2018) A linear programming based algorithm to solve a class of optimization problems with a multi-linear objective function and affine constraints. Comput Oper Res 89:17-30. https://doi.org/10.1016/j.cor.2017. 07.015

60. Acuna JA, Zayas-Castro JL, Charkhgard H (2020) Ambulance allocation optimization model for the overcrowding problem in us emergency departments: a case study in Florida. Socio Econ Plan Sci:71. https://doi.org/10.1016/j.seps.2019.100747

61. Bakalikwira L, Bananuka J, Kaawaase Kigongo T et al (2017) Accountability in the public health care systems: a developing economy perspective. Cogent Bus Manag 4(1):1334995. https://doi.org/10.1080/23311975.2017.1334995

62. Berwick DM (2016) Era 3 for medicine and health care. JAMA 315(13):1329-1330. https://doi.org/10.1001/jama.2016.1509

63. Lee YH, Choi YH (2020) Optimal cost adjustment for a selfish routing healthcare network. Health Care Manag Sci 23(4):585604. https://doi.org/10.1007/s10729-020-09512-6

64. Roughgarden T (2003) The price of anarchy is independent of the network topology. J Comput Syst Sci 67(2):341-364. https://doi.org/10.1016/S0022-0000(03)00044-8

65. Chua L, Kang SM (1977) Section-wise piecewise-linear functions: Canonical representation, properties, and applications. Proc IEEE 65(6):915-929. https://doi.org/10.1109/proc.1977.10589

66. Lee J, Leyffer S (2011) Mixed integer nonlinear programming, vol 154. Springer Science \& Business Media. https://www.springer. $\mathrm{com} / \mathrm{series} / 811$

67. Gobierno de Chile (2020) Portal de transparencia en salud. https:// portaltransparencia.cl/PortalPdT/

68. Alarcón Rojas G, Navarro Duarte C, Muñoz López S et al (2018) Plan nacional de tiempos de espera no GES en Chile en modelo de atención RISS. http://54.148.75.48/handle/123456789/3578

69. Yang J, Rahardja S, Fränti P (2019) Outlier detection: how to threshold outlier scores? Proc Int Conf Artif Intell Inf Process Cloud Comput:1-6. https://doi.org/10.1145/3371425.3371427 
70. Clinicas de Chile (2017) Dimensionamiento del sector de salud privado en Chile. http://www.clinicasdechile.cl/

71. Subsecretaría de Salud Pública (2020) Estudio de verificacion del costo esperado individual promedio por beneficiario del conjunto priorizado de problemas de salud con garantías explícitas - 2015. http://biblioteca.digital.gob.cl/handle/123456789/2328

72. Clínica Bupa (2019) Arancel particular clínica Bupa Santiago. https://www.clinicabupasantiago.cl/clinica_santiago/ nuestros-aranceles-2019

73. Servicio de Salud Osorno (2021) Servicio de Salud Osorno obtiene primer lugar nacional en Compromisos de Gestión 2020. https://ssosorno.cl/category/sin-categoria/destacados/

74. Departamento de Control de Gestión Gabinete Subsecretaría de Redes Asistenciales (2020) Compromisos de Gestión 2020. https://www.ssbiobio.cl/Archivos/Transparencia_Activa/Gestion_ Institucional/2020/Orientaciones_Tecnicas_COMGES_2020.pdf

75. Barrow RY, Ahmed F, Bolan GA et al (2020) Recommendations for providing quality sexually transmitted diseases clinical services, 2020. MMWR Recommend Rep 68(5):1. https://doi.org/10. 15585/mmwr.rr6805a1

76. US Department of Health and Human Services (2019) Sexually transmitted disease surveillance 2018. https://www.cdc.gov/std/ stats18/STDSurveillance2018-full-report.pdf

77. du Prel JB, Puppe W, Gröndahl B et al (2009) Are meteorological parameters associated with acute respiratory tract infections? Clin Infect Dis 49(6):861-868. https://doi.org/10.1086/605435

78. Liu Y, Liu J, Chen F et al (2016) Impact of meteorological factors on lower respiratory tract infections in children. J Int Med Res 44(1):30-41. https://doi.org/10.1177/0300060515586007

79. Brezzi M, Luongo P (2016) Regional disparities in access to health care: a multilevel analysis in selected OECD countries. OECD Regional Development Working Papers https://doi.org/10.1787/ 5jm0tn1s035c-en
80. Gusmano MK, Weisz D, Rodwin VG et al (2014) Disparities in access to health care in three french regions. Health Policy 114(1):31-40. https://doi.org/10.1016/j.healthpol.2013.07.011

81. Joyce DL, Conte JV, Russell SD et al (2009) Disparities in access to left ventricular assist device therapy. J Surg Res 152(1):111117. https://doi.org/10.1016/j.jss.2008.02.065

82. Wara M (2007) Is the global carbon market working? Nature 445:595-596. https://doi.org/10.1038/445595a

83. De Wolf AH, Toebes B (2016) Assessing private sector involvement in health care and universal health coverage in light of the right to health. Health Hum Rights 18(2):79-92. https://www. ncbi.nlm.nih.gov/pmc/articles/PMC5394993/

84. Charkhgard H, Keshanian K, Esmaeilbeigi R et al (2020) The magic of Nash social welfare in optimization: do not sum, just multiply. Preprint http://www.optimization-online.org/DB_ HTML/2020/03/7688.html

85. Sierra-Altamiranda A, Charkhgard H, Eaton M et al (2020) Spatial conservation planning under uncertainty using modern portfolio theory and Nash bargaining solution. Ecol Model:423. https://doi.org/10.1016/j.ecolmodel.2020.109016

86. Ministerio de Salud Chile (2020) Dispone instrucciones para la coordinación de la red pública y privada de salud por parte de la Subsecretaría de Redes Asistenciales. https://www.minsal.cl/ wp-content/uploads/2020/04/1747890.pdf

87. Rotarou ES, Sakellariou D (2017) Neoliberal reforms in health systems and the construction of long-lasting inequalities in health care: a case study from chile. Health Policy 121(5):495-503. https://doi.org/10.1016/j.healthpol.2017.03.005

Publisher's note Springer Nature remains neutral with regard to jurisdictional claims in published maps and institutional affiliations. 